\title{
Multi-Lead Ahead Prediction Model of Reference Evapotranspiration Utilizing ANN with
}

\section{Ensemble Procedure}

Ahmed El-Shafie ${ }^{1}$, Heerbod Jahanbani ${ }^{2}$, Ali Najah ${ }^{3}$

Authors are grateful to the Reviewer for His/Her in-depth comments to the paper and for raising interesting questions. All the comments are addressed accordingly and have been incorporated to the revised manuscript (underline). Detailed responses to the comments and recommendations are as follows.

\section{Editorial Comments:}

The authors need to revise their paper so that it addresses carefully all the questions and criticisms of the two referees.

Generally, due to limited space, papers are given priority which are closest to the journal's scope and contents. There is a question of relevancy, i.e., whether SERRA readers will benefit maximally by a paper that does not show strong evidence of relevancy to the journal's contents. The authors need to link their paper's analysis to works that have appeared in SERRA.

\section{Reply}

Owing to the editor feedback, the authors cite several relevant researches that have been published in SERRA ( 4 references), we believe that the readers of the SERRA will get benefits from our research reported in this manuscript as it focus of evapotranspiration prediction model as it one of the stochastic natural parameter.

1Associate Professor, Dept. of Civil and Structural Eng., Faculty of Engineering, University Kebangsaan Malaysia, Malaysia

${ }^{2} \mathrm{PhD}$ Candidate, infrastructure department, Faculty of Engineering, University of Melbourne, Australia 3 Post Doctorate, Dept. of Civil and Structural Eng., Faculty of Engineering, University Kebangsaan Malaysia, Malaysia 


\section{Reviewer \#1:}

The authors aimed to propose several over-fitting procedures have been augmented with the classical ANN model. The subject matter is within the scope of the journal. The manuscript could be published with some changes; here are some suggestions and recommendations:

\section{Reply}

The authors appreciate the opinion of the referee on our research and thank him for his positive comments that will strengthen the content of our research manuscript.

1- Introduction: The review of literature is a little bit short and need to add recent papers on reference evapotranspiration in Iran especially in humid climate. The following literatures are recommended to the authors:

Fooladmand HR (2011) Evaluation of some equations for estimating evapotranspiration in the south of Iran. Arch Agron Soil Sci 57(7):741-752

Rahimi Khoob, A., Behbahani M.B., Fakheri J. (2012) An Evaluation of Four Reference Evapotranspiration Models in a Subtropical Climate. Water Resources Management 26(10): 2867-2881.

Razzaghi F, Sepaskhah AR (2010) Assessment of nine different equations for ETo estimation using lysimeter data in a semi-arid environment. Arch Agron Soil Sci 56(1):1-12

Sabziparvar, A. A., Tabari, H. (2010) "Regional estimation of reference evapotranspiration in arid and semi-arid regions". Journal of Irrigation and Drainage Engineering ASCE 136(10):724731

Tabari, H. (2010) "Evaluation of reference crop evapotranspiration equations in various climates". Water Resources Management 24:2311-2337

Tabari, H., Grismer, M. E., Trajkovic, S. (2011) "Comparative analysis of 31 reference evapotranspiration methods under humid conditions". Irrigation Science doi: 10.1007/s00271011-0295

Tabari H., Martinez, C., Ezani, A., Hosseinzadeh Talaee, P. (2012) "Applicability of support vector machines and adaptive neurofuzzy inference system for potato crop evapotranspiration forecasting". Irrigation Science doi: 10.1007/s00271-012-0332-6

Tabari, H., Hosseinzadeh Talaee, P. (2012) "Multilayer Perceptron for Reference Evapotranspiration Estimation in a Semiarid Region". Neural Computing \& Applications doi: 10.1007/s00521-012-0904-7 


\section{Reply:}

The authors carefully reviewed those recommended references. All the above mentioned references have been reviewed and reported in the revised manuscript.

2- Materials and methods: The use of a temperature based approach for estimating RS introduces considerable uncertainty in the use of the PMF-56 method. It seems that the empirical adjustment factor may vary from region-to-region. An attempt to validate the method of Hargreaves for radiation estimation based on temperature range would be valuable.

\section{Reply}

The authors agreed with the reviewer in this comment. Keep in mind that this research is focusing on the over-fitting problem experienced in the ANN modeling, reference data whether it include uncertainty or not, the model process should treat it via its mathematical procedure. Therefore, the authors do not focus on the empirical adjustment on reference data used but focusing on the prediction of the model accuracy after considering several methods of remove the over-fitting that experienced in ANN modeling.

On this context, the conclusion section highlight this point to be consider for future research and how the uncertainty in PMF-56 method could be investigated.

3- Results and discussion: "In this study, the proposed ENN compared with Hargreaves and Samani (1985) (HGS) model and showed the ENN provides more accurate prediction for ETo". Similar results were reported by Rahimi Khoob (2008) in semi-arid climate in Iran. It is interesting to compare the results of this study with those of Rahimi Khoob, A (2008) Comparative study of Hargreaves's and artificial neural network's methodologies in estimating reference evapotranspiration in a semiarid environment. Irrig Sci 26(3):253-259

\section{Reply}

The paper by Rahimi Khoob (2008) has been reviewed by the authors and a comparison analysis with the research reported in this manuscript has been carried out.

Compared with the results reported in the previous research, Khoob (2007) developed a neural network method in order to estimating monthly ETo at Khuzestan plain, located in the southwest of Iran. In this study, the maximum and minimum air temperatures $\left({ }^{\circ} \mathrm{C}\right)$ and the extraterrestrial radiation ( $\mathrm{mm}$ day-1) were adopted as input variables for the ANN. The developed model it gave reliable estimation in this study. However, regardless of the results that obtained, some definite problems such as over-fitting can occur especially when number of nodes in the hidden layer is determined by trial and error. (Reuter and Möller, 2010; Graf et al, 2010; Daniel et al, 2010) Therefore, in order to avoid an over-fitting problem, several over-fitting procedures have been augmented with the classical ANN 
model, are proposed in this research, The number of nodes in the hidden layer was determined by trial and error.

4- The authors must demonstrate the paper's relevancy by connecting their paper with relevant papers that have been previously published in SERRA.

Reply:

The literature, problem statement and objectives of this research have been has been modified to include relevant research manuscript that published in SERRA and explained clearly in the revised manuscript

\section{$\underline{\text { Reviewer \#2 }}$}

This paper presents a very valuable effort to introduce ANN technique with Ensemble Procedure in the application of Prediction Model of Evapotranspiration, which could be very useful in modeling

process.

The paper proposes a modification of classical artificial neural networks, called ensemble neural network, in order to improve the capacity of ANN models to map non-linear phenomena; among the aim of the paper is also to overcome over-fitting to training data. A number of ANN models (with or without avoiding over-fitting techniques and ENN) are compared on the prediction of daily potential evapotranspiration at Rasht city, in Iran, starting from the minimum and maximum daily temperature of the region collected from 1975-1988.

\section{Reply}

The authors thank the reviewer for his/her opinion regarding our research contribution reported in this manuscript.

C.1- The problem statement and objective are not explained clearly. It needs to be presented in specific and detailed way.

Reply:

The problem statement and objectives of this research have been explained clearly in the revised manuscript. 
C.2- Auto-Regression Moving Average (ARMA) is partly difficult to follow and too short to be useful to the readers. Can it be expanded to cover the basic principles.

Reply:

We agreed with the reviewer, in this context, more detailed has been added in the revised manuscript.

C.3- Section 4.2 (Artificial Neural Networks) is well written, but unfortunately this section is quite short and important points are missing. This would be the place to discuss in more detailed Artificial Neural Networks techniques used, especially on the training procedure.

Reply:

Owing to the reviewer's feedback, the structure of ANN has been significantly improved and more detailed has been added in the revised manuscript.

C.4- In the conclusion section, the limitations of this study, suggested improvements of this work and future directions should be highlighted.

\section{Reply:}

The conclusion section has been significantly improved and more rigorous discussion on the advantages and limitations of the method has been added in the revised manuscript. 


\title{
Multi-Lead Ahead Prediction Model of Reference Evapotranspiration Utilizing ANN with Ensemble Procedure
}

\author{
Ahmed El-Shafie ${ }^{4}$, Heerbod Jahanbani ${ }^{5}$, Ali Najah ${ }^{6}$
}

\author{
Ahmed El-Shafie, $\mathrm{PhD}$ \\ Smart Engineering System Research Group \\ Department of Civil \& Structural Engineering \\ Faculty of Engineering and Built Environment \\ University Kebangsaan Malaysia \\ 43600 UKM Bangi, Selangor Darul Ehsan \\ MALAYSIA
}

Tel. +60 (3) 89217013

Fax +60 (3) 89216147

e-mailelshafie@eng.ukm.my

4Associate Professor, Dept. of Civil and Structural Eng., Faculty of Engineering, University Kebangsaan Malaysia, Malaysia

${ }^{5} \mathrm{PhD}$ Candidate, infrastructure department, Faculty of Engineering, University of Melbourne, Australia 6 Post Doctorate, Dept. of Civil and Structural Eng., Faculty of Engineering, University Kebangsaan Malaysia, Malaysia 


\title{
Multi-Lead Ahead Prediction Model of Reference Evapotranspiration Utilizing ANN with Ensemble Procedure
}

\author{
Ahmed El-Shafie ${ }^{1}$, Heerbod Jahanbani ${ }^{2}$, Ali Najah ${ }^{3}$
}

\begin{abstract}
Obtaining an accurate estimate of the reference evapotranspiration $\left(\mathrm{ET}_{\mathrm{o}}\right)$ can be difficult, especially when there is insufficient data to utilize the Penman-Monteith method. Artificial intelligence-based methods may provide reliable prediction models for several applications in engineering. However, time-series prediction based on artificial neural network (ANN) learning algorithms is fundamentally problematic. For example, the ANN model can experience overfitting during training and, in consequence, lose its generalization. In this research, several overfitting procedures have been augmented with the classical ANN model, are proposed. This model was applied to the prediction of the daily $\mathrm{ET}_{\mathrm{o}}$ at Rasht city, located in the north part of Iran, by using the minimum and maximum daily temperature of the region collected from 1975-1988. In addition, three different scenarios have been developed in order to achieve better prediction accuracy. The results showed that the proposed ENN model successfully predicted the daily $\mathrm{ET}_{\mathrm{o}}$ with a significant level of accuracy using only the maximum and minimum temperatures. The model also outperformed the classical ANN method. In addition, the proposed ENN compared with Hargreaves and Samani (1985) (HGS) model and showed the ENN provides more accurate prediction for $\mathrm{ET}_{\mathrm{o}}$. Furthermore, the proposed model could provide relatively good level of accuracy when examined for multi-lead predictions, which could not be afford by HGS model.
\end{abstract}

Keywords: evapotranspiration, neural network, ensemble neural network, over-fitting, Rasht City (Iran) 


\section{List of abbreviations}

ANN: Artificial Neural Networks

$\mathrm{R}^{2}$ : Correlation coefficient

ENN: Ensemble Neural Network

$\mathrm{ET}_{\mathrm{o}}$ : Reference Evapotranspiration

FFBP: Feed-Forward Back-Propagation

HGS: Hargreaves and Samani

IN: Iteration Number

LVC: Low Value Criteria

MARE: Mean Absolute Relative Error

MAE: Mean Absolute Error

MSE: Mean Square Error

PVC: Peak Value Criteria

PM: Penman-Monteith

Rs: Solar Radiation

Ra: Extraterrestrial Radiation

$\mathrm{T}_{\text {min }}$ : Minimum Temperature

$\mathrm{T}_{\text {mean }}$ : Mean Temperature

$\mathrm{T}_{\text {max }}$ : Maximum Temperature 


\section{Introduction}

\subsection{Background}

Many parts of the earth, especially arid and semi-arid areas, face a lack or a shortage of water, due to global increases in population, industrialization and climate change, and high $\mathrm{CO}_{2}$ emissions (IPCC, 2007). The accurate estimation of the reference evapotranspiration $\left(\mathrm{ET}_{\mathrm{o}}\right)$, one of the main parameters of the hydrological cycle, is vital for various fields of study, such as hydrologic water balance, irrigation system design and management, crop yield simulations, water resource planning, and improving water usage and optimizing water loss in agriculture.

Evapotranspiration consists of evaporation and transpiration processes. In the evaporation process, water is changed to water vapor (vaporization) and is removed from the evaporating surface (vapor removal), which may include oceans, lakes, seas, rivers, pavements, soil, wet vegetations, etc. This process is affected by many climatologic parameters, such as solar radiation, air temperature, air humidity, and wind speed (Gao et al, 2012; Telesca et al, 2012). Transpiration is the vaporization of liquid water contained in plant tissue, through the plant stomata. Transpiration, like evaporation, depends on many factors, including the energy supply, vapor pressure gradient, wind, radiation, air temperature, air humidity, soil water content, water logging, soil water salinity, crop characteristics, environmental aspects, cultivation practices, and the ability of the soil to conduct water to the roots. Evaporation and transpiration occur simultaneously, and there is no easy way to separate them (Yang et al, 2009; Bulygina \& Gupta 2010; Zhang et al, 2011). For example, when a crop is small, the main process for losing water is evaporation; however, once the crop is completely developed and covers the soil, transpiration becomes the main process. 


\subsection{Brief review of previous studies}

According to Sudheer et al, (2003), the main advantage of using artificial neural networks (ANNs) is that they, unlike conventional methods, do not need detailed information on the physical processes of the system. Many studies have successfully applied ANNs to the estimation of different phases of the hydrological cycle, such as rainfall runoff modeling (Hsu et al. 1995; Fernando and Jayawardena 1998; Tokar and Johnson 1999; Elshorbagy et al. 2000; Liong et al. 2001); groundwater level (Birkinshaw et al, 2008 and Ioannis et al, 2008); Wave height prediction (Ahmadreza et al, 2009); predicting monsoon rainfall (Surajit and Goutami, 2008); modeling in a cold and snowy climate (Yonas and Coulibaly, 2008); streamflow prediction (Clair and Ehrman 1998; Alexandra and Asaad 2009); reservoir inflow forecasting (Jain et al. 1999; Coulibaly et al. 2000); prediction of water quality parameters (Maier and Dandy 1999); and the estimation of evapotranspiration (Odhiambo et al. 2001; Kumar et al. 2002; Trajkovic et al. 2003; Sudheer et al, 2003; Awchi 2007; Zanetti et al. 2007; Wang and Kerh 2008; Jain et al. 2008; Khoob 2008; Marti et al. 2008; Kisi 2009; Chauhan and Shrivastava 2009).

Awchi (2007) emulated evapotranspiration by means of ANN and daily climatic data (e.g., temperature, relative humidity, sunshine hours, wind speed, and rainfall). They compared their findings with those of the Penman-Monteith (PM) method, and reported that ANN could successfully be utilized for estimating $\mathrm{ET}_{\mathrm{o}}$. Chauhan and Shrivastava (2008) showed that ANN models perform better at estimating $\mathrm{ET}_{\mathrm{o}}$ than climatic models such as the Blaney-Criddle, Radiation, Modified Penman, and Pan Evaporation models. The results also suggested that ANN models could estimate $\mathrm{ET}_{\mathrm{o}}$ from the maximum and minimum temperatures. Applying a sequentially adaptive radial-basis function network for forecasting the mean monthly $\mathrm{ET}_{\mathrm{o}}$, 
Trajkovic et al. (2003) reported that ANN could predict the monthly ET with high accuracy. Sudheer et al, (2003) checked the potential of ANN for estimating the monthly actual crop evapotranspiration from limited climatic data. Their research employed a radial-basis functiontype ANN and compared the results with those measured by lysimeter. Their study clearly showed that the ANN could successfully estimate evapotranspiration with limited climate data.

Wang and Kerh (2008) used a feed-forward back-propagation (FFBP) ANN to estimate the average decadal $\mathrm{ET}_{\mathrm{o}}$ with the maximum and minimum temperatures in Burkina Faso. The output of their ANN had a higher accuracy than those of Hargreaves (HGS) and Blaney-Criddle. Zanetti et al. (2007) applied ANN to the estimation of the daily $\mathrm{ET}_{\mathrm{o}}$ as a function of maximum and minimum temperature, extraterrestrial radiation, and daylight. Khoob (2008) compared a method of converting pan evaporation with ANN by utilizing the maximum and minimum temperatures, showing that ANN provided more accurate results than the conversion method Tabari and Hosseinzadeh (2012), Sabziparvar and Tabari, (2010), and Fooladmand (2011). In addition, Johnson and Sharma (2010) proved that the importance of including the wind in predicting the PET due to the fact of the effect of energy. However, in some study areas, information about the wind parameter might be not available and then it is necessary to rely on the accessible data. $\underline{\text { Khoob, et al, (2012) compared four equation for estimating ET0 including Makkink (MK), Turc }}$ (TC), Priestley-Taylor (PT) and Hargreaves (HG). The data was collected from 8 stations (one of them is our station "Rasht"). Obviously, again the difference is there is ANN in this study and no improvement of performance.

Tabari, (2010), Tabari, et al (2011), Tabari, et al (2012), compared the four equations of Khoob el al. (2012) on estimating ETo. Generally, his results showed that the Makkink and Priestley- 
Taylor models estimated ETo values less accurately than Turc and Hargreaves models for the all climates. Again the difference is there is ANN in this study and no improvement of performance.

For improving over-fitting problem, Giustolisi and Laucellieight (2005) applied and compared different avoiding over-fitting techniques for studying rainfall-runoff modeling and concluded techniques based on smoothing mapping of the function underlying the physical phenomena generally perform well. Giustolisi and Simeone (2006) introduced an innovative multi-objective based approach for optimizing design of ANN by minimizing the model input dimension, the hidden neuron number and the generalization error computed on a validation set of data for the case of groundwater level prediction.

\subsection{Problem statement and objective}

The use of artificial neural networks (ANNs) in prediction of evapotranspiration has received vast interest in the present decade. Several methodologies have been adopted in the literature to realize the ANN modelling of evapotranspiration process. Although ANN models have proven to be efficient, their convergence tends to be very slow and yields suboptimal solutions, which may be unsuitable for dynamic adaptive accurate forecasting purposes (ElShafie et al, 2011; Noureldin et al, 2011). Chowdhury, and Sharma (2009) discussed a wide range of cross-validation methods in order to enhance the accuracy level of river flow forecasting model and avoiding over-fitting. Indeed, the major objective of training an ANN for prediction is to generalize: i.e., to have the outputs of the network approximate target values, given inputs that were not in the training set. However, time-series prediction based on ANN learning algorithms is fundamentally difficult and faces problems. Notably, the ANN model faces the problem of over-fitting while training and, consequently, may lose its generalization. 
ETo is a complex process depending on several interacting climatological factors, such as temperature, humidity, wind speed, and radiation. The lack of physical understanding of ETo process and unavailability of all relevant data results in inaccurate estimation of ETo (Kumar et al., 2002). Although these data are available in this study (and were used in the PM method), this research suggest model able to determine ETo in places where such data are not available. The main objective of this research is to introduce a modification for the classical neural network modeling, namely the ensemble neural network (ENN) in order to overcome the problem of over-fitting. Moreover, this manuscript investigates the potential of utilizing the ENN model to estimate and predict the monthly time-series of daily $\mathrm{ET}_{0}$ at Rasht City, Iran. The proposed ENN will use only the daily time-series of minimum and maximum temperatures and solar radiation $\underline{T_{\underline{m i n}}}, T_{\underline{\max }}$, and $R_{\underline{s}}$, respectively) as the input pattern. Since there was no lysimeter installed in the case study area, the $\mathrm{ET}_{0}$ calculated with the PM method was accepted as the reference $\mathrm{ET}_{0}$ to evaluate the proposed ENN model. The anticipated impact of this model is that it can predict the monthly time-series of daily $\mathrm{ET}_{\mathrm{o}}$ similar to the level of accuracy of the PM method, where the internal hydrologic parameters or many climatic parameters explicitly are neglected

\section{Material and Methods}

\subsection{Study area}

The north part of Iran, near the Caspian Sea, has a unique climate and plant cover compared to other parts of Iran. It has cold and humid weather in the winter and fall, and hot and humid weather in the summer. This region receives the most precipitation of all regions in Iran, with a maximum annual precipitation of $1400 \mathrm{~mm}$ per year recorded in Anzali City in Gilan province. The principal agricultural product in this region is rice, which has a high crop water requirement. This region contains three provinces: Gilan, Mazandaran, and Golestan. The case study is Rasht, 
the capital city of Gilan province, located in the west of the region. The geographical location of this province is from $36^{\circ} 34^{\prime}$ to $38^{\circ} 27^{\prime} \mathrm{N}$ and from $48^{\circ} 53^{\prime}$ to $50^{\circ} 34^{\prime} \mathrm{S}$. Its area is $14,711 \mathrm{~km}^{2}$ with a population of 2.4 million people (Figure 1 ).

\subsection{Climate data}

For the purposes of this study, daily meteorological parameters, including the daily $\mathrm{T}_{\min }$, $\mathrm{T}_{\max }$, and mean temperature $\left(\mathrm{T}_{\text {mean }}\right)\left({ }^{\circ} \mathrm{C}\right)$, dew point $\left({ }^{\circ} \mathrm{C}\right)$, mean relative humidity $(\%)$, wind speed (knot), sunshine (hour/day) and actual vapor pressure (mbar) for the Rasht station (latitude: $37^{\circ} 12^{\prime} \mathrm{N}$, longitude: $49^{\circ} 39^{\prime} \mathrm{E}$, elevation: $36.7 \mathrm{~m}$ above sea level) were collected for 14 years (from 1 Jan 1975 to 31 Dec 1988).

The input data for training and simulation were $\mathrm{T}_{\max }, \mathrm{T}_{\min }$, and Rs. In the case where only the $\mathrm{T}_{\max }$ and $\mathrm{T}_{\min }$ were available, $R s$ was calculated from:

$$
R_{S}=K_{R s} \sqrt{\left(T_{\max }-T_{\min }\right)} R_{a}
$$

where $R_{s}$ is the solar radiation $\left(\mathrm{MJ} \mathrm{m}^{-2} \mathrm{~d}^{-1}\right) ; K_{R s}$ is an adjustment coefficient (0.16-0.19); and $R a$ is the extraterrestrial radiation $\left(\mathrm{MJ} \mathrm{m}^{-2} \mathrm{~d}^{-1}\right)$ (Eqn. 2).

\section{Estimation of reference evapotranspiration}

The PM equation for computation of the reference evapotranspiration was proposed by Allen et al. (1998) as:

$E T_{o}=\frac{0.408 \Delta\left(R_{n}-G\right)+\gamma \frac{900}{T+273} u_{2}\left(e_{s}-e_{a}\right)}{\Delta+\gamma\left(1+0.34 u_{2}\right)}$

where $E T_{o}$ is the reference evapotranspiration $\left(\mathrm{mm} \mathrm{day}^{-1}\right) ; R_{n}$ is the net radiation at the crop surface $\left(\mathrm{MJ} \mathrm{m}^{-2}\right.$ day $\left.^{-1}\right) ; G$ is the soil heat flux density $\left(\mathrm{MJ} \mathrm{m}^{-2}\right.$ day $\left.^{-1}\right) ; T\left({ }^{\circ} \mathrm{C}\right)$ and $u_{2}\left(\mathrm{~m} \mathrm{~s}^{-1}\right)$ are the mean daily air temperature and wind speed, respectively, at a height of $2 \mathrm{~m} ; e_{s}$ and $e_{a}$ are the 
saturation and actual vapor pressure, respectively $(\mathrm{kPa})$; $\mathrm{e}_{\mathrm{s}}-\mathrm{e}_{\mathrm{a}}$ is the saturation vapor pressure deficit $(\mathrm{kPa}) ; \Delta$ is the slope of the vapor pressure curve $\left(\mathrm{kPa}{ }^{\circ} \mathrm{C}^{-1}\right)$; and $\gamma$ is a psychrometric constant $\left(\mathrm{kPa}^{\circ} \mathrm{C}^{-1}\right)$.

In the case where only $T_{\max }$ and $T_{\min }$ are available, Hargreaves and Samani (1985) suggested that $E T_{o}$ can be calculated as:

$$
E T_{o}=C_{o}\left(T_{\max }-T_{\min }\right)^{0.5}\left(T_{\text {mean }}+17.8\right) R_{a}
$$

where $E T_{o}$ is the reference evapotranspiration calculated by the HGS method ( $\mathrm{mm} /$ day).

The daily PM was calculated with the FAO $E T_{o}$ calculator (version 3.1 January 2009). The timeseries input data of PM employed in the software and the daily $E T_{o}$ values over 13 years were generated and sorted into monthly time-series.

\section{Methodology}

\subsection{Auto-Regression Moving Average (ARMA)}

The ARMA model developed utilizing the same temperature data. These data was analyzed in the time-domain with fitting a model of the following form

$$
\underline{y_{t}=\phi_{1} y_{t-1}+\ldots+\phi_{p} y_{t-p}+\theta_{1} \varepsilon_{t-1}+\ldots \phi_{q} \varepsilon_{t-q}+\varepsilon_{t}+\delta}
$$

which best predicts the values of variable $\mathrm{Y}$ at time $\mathrm{t}$ based on previous observations, $y_{t-1} \ldots y_{t-p}$

previous error terms $\varepsilon_{t-1} \ldots \varepsilon_{t-q}$, and a constant, $\underline{\delta}$. The q values are collectively referred to as $\underline{\text { the autoregressive part of the model (of order p), whereas }} \underline{\theta}$ 's constitute the moving-average $\underline{\text { component (of order q). The inclusion of a nonzero }} \underline{\delta}$ introduces a deterministic trend in the model. We refer to an autoregressive-moving-average model (ARMA ( $p, q)$ ), and we are concerned with identifying the order of the model and estimating its coefficients. Models in 
which there are no moving-average terms (i.e., $q=0)$ are simply called autoregressive $(A R(p))$, whereas moving-average models (MA(q)) are those with no autoregressive components. The ARMA models of order $(p, q)$ yields superior results to either pure MA or AR forms.

\subsection{Artificial neural networks}

ANNs are densely interconnected processing units that utilize parallel computation algorithms. The basic advantage of using an ANN is that it can learn from representative examples without requiring special programming modules to simulate special patterns in the dataset (Gibson and Cowan, 1990). This advantage allows ANNs to learn and adapt to a continuously changing environment. Therefore, the ANN can be trained to perform a particular function by tuning the values of the weights (connections) between these elements. The training procedure of ANN is performed so that a particular input leads to a certain target output. One of the applications of the ANN is function approximation; by training the ANN, connections (weights) between the input and output are adjusted until the output is similar to the target. Because of its nonlinear correlation, ANN is a powerful implement for estimating complicated functions such as $\mathrm{ET}_{\mathrm{o}}$. One of the most commonly used ANNs for a hydrological purpose is Feed Forward Back Propagation (FFBP), which uses the Widrow-Hoff learning rule that the network weights move along a negative gradient of the performance function (Adeli and Hung, 1995; Adeli and Vishnubhotla, 1992; Todorovic, et al, 2000; Samant and Adeli, 2000).

The training algorithm applied was based on Levenberg-Marquardt optimization, which minimizes the combination of error and weights to reach the best combination. Back-propagation was applied to compute the Jacobian $j_{x}$ of the performance with respect to the weight and bias variables $X$. Each variable was adjusted according to Levenberg-Marquardt:

$j_{j}=j_{x} \times j_{y}$ 
$j_{e}=j_{x} \times E$

$d_{x}=\left(j_{j}+I \times m u\right) / j_{e}$

where $E$ is all errors; $I$ is the identity matrix; $d_{x}$ is the derivatives of performance with respect to the weight and bias variables $X$; and $j_{e}$ is the Jacobian times errors.

\subsection{ANN Modeling Scenario for $\mathbf{E T}_{0}$}

Actual $T_{\max }, T_{\min }$, and $R_{s}$ data were collected daily over the 14 years between 1975 and 1988 at Rashat City, Iran. The $\mathrm{ET}_{\mathrm{o}}$ was calculated based on the PM method. These data were used to train, test, and validate the proposed model. In fact, the data splitting into to these three stages in order to evaluate the proposed model. The training session is for building the model, the testing session is considered for initial examination of the model performance utilizing unseen dataset, while the validation session is considered to evaluate the consistency of the model performance with another unseen data input set. It can be observed from the data collected during this period that the model experienced all possible patterns of $\mathrm{ET}_{\mathrm{o}}$, which substantiates the reliability of the proposed model accuracy (Fig. 2).

Generally, the ANN modeling method uses the previous and most recent behavior of a system to predict its future changes for a particular parameter. The major advantage of this method is its ability to predict the behavior of systems without analytical prediction rules. However, a major obstacle is the need to select the ANN architecture (in terms of the inputoutput pattern) that will provide the best result for the desired output.

The model structure is organized utilizing daily data for each month individually. In other word, for each month ( 30 days average), the data length is 30 days $* 11$ years $=330$ data records) then we use 9 years data for training (270 data records) and one year for validation ( 30 records) 
finally one year for testing (30 records data). Three different scenarios of the network architecture were applied to predict the daily $\mathrm{ET}_{\mathrm{o}}$ at Rasht City, Iran. Scenario I was organized such that the prediction of $E T_{o}$ at a particular day $t($ for certain month) and year $n$ was based on the $\mathrm{T}_{\max }, \mathrm{T}_{\min }$, and $\mathrm{R}_{\mathrm{s}}$ at month $t-1$ and year $n$, as follows:

$$
E T_{o}(t, n)=f\left(T_{(t-1, n)}^{\max }, T_{(t-1, n)}^{\min }, R_{(t-1, n)}^{s}\right)
$$

Scenario II was structured as the prediction of $E T_{o}$ at day $t$ (for certain month) and year $n$ based on the $\mathrm{T}_{\max }, \mathrm{T}_{\min }$, and $\mathrm{R}_{\mathrm{s}}$ of the same day for year $n-1$ :

$$
E T_{o}(t, n)=f\left(T_{(t, n-1)}^{\max }, T_{(t, n-1)}^{\min }, R_{(t, n-1)}^{s}\right)
$$

The architecture of the scenarios II is a 3-layer network, including an input layer, output layer, and hidden layer (Figure 3). The input layer consists of 3 neurons (corresponding to the monitored $T_{\max }, T_{\min }$, and $R_{s}$ ). The output layer consists of 1 neuron (corresponding to the predicted $\mathrm{ET}_{\mathrm{o}}$ ). The architecture also contains a number of hidden layers with an arbitrary number of neurons at each layer. To achieve the desired forecasting accuracy, 12 ANN architectures were developed (1 per month). Daily $\mathrm{T}_{\max }, \mathrm{T}_{\min }, \mathrm{R}_{\mathrm{s}}$, and $\mathrm{ET}_{\mathrm{o}}$ values for the 10 years from 1975 to 1985 were utilized to train the 12 networks. The performance and reliability of the ANN models were examined with the data monitored between 1986 and 1987. The capabilities of the developed ANN models were further verified for the year 1988.

Furthermore, the third scenario III, the input pattern including different historical records of the $T_{\max }, T_{\min }$, and $R_{s}$ has been examined as shown in figure 4 . In fact, scenario III could be considered as an extension for scenario II with considering historical data records as input pattern. Such decision was based on that the scenario II is outperformed scenario I. Figure 4 shows the architecture of the scenario III that include temporal pattern for the input parameters. 
Such pattern is achieved by introducing delays $1 \mathrm{t}$ through $\mathrm{P}_{\mathrm{t}}$. For simplification, $\mathrm{t}$ is dropped and a unit delay operator is represented. The inputs $X_{1}(t), \ldots, X_{N}(t)$ represent the $N$ dimensions of the vector $X_{b}(t)$ (in our application is the past $T_{\max }, T_{\min }$, and $R_{s}$ ) at time $t$ and $\left(P_{-} 1\right)$ is the number of the successive vectors $X_{b}$ which define the temporal window size to which the neuron reacts. Different values of $\mathrm{P}$ have been evaluated in this study.

One of the most important aspects of machine learning models is how well the model generalizes to unseen data. Over-fitting occurs when a neural network loses its generalization: that is, it cannot generalize the relationships that exist between training inputs and their related outputs to similar hidden patterns in the unobserved data. In such cases, the performance of the neural network measured on the training set is much better than that on new inputs. When predicting a time-series, the aim is to be able to deal with time-varying sequences. This goal can be achieved if the network input-output patterns involved can respond to temporal sequences, such that networks within its structure should be considered as good choices. However, regardless of the architecture used, some definite problems such as over-fitting can occur (Tetko, et al, 1995; Haykin, 1994; Bishop, 1996; Duda R. O., Hart and Stork, 2001; Box and Jenkins 1970; Reuter and Möller, 2010; Graf et al, 2010; Daniel et al, 2010).

\subsection{Network over-fitting}

Over-fitting has been addressed with techniques such as weight decay, weight elimination, and early stopping (Weigend, et al, 1992; Drucker et al, 1994). Among these methods, earlystopping is the most well-known solution (Prechelt, 1998). However, using this method on a time-series of a complex system stops the training process too early, and decreases the chance of detecting meaningful relationships between the network outputs and the actual behavior of the system. As a result, the resulting model will not have proper features for predicting the time- 
series of the behavior of the system. In the proposed method, we do not focus on removing the over-fitting problem for a single neural network; instead, the major goal is to find an algorithm that can be applied on the outputs of the over-fitted networks to produce the correct results. This algorithm will be presented in the following sections.

Here, to avoid an over-fitting problem, we utilized the regularization technique (Nordström and Svensson, 1992). This is known as a suitable technique when the scaled conjugate gradient descent method is adopted for training, as is the case in this study. The regularization technique involves modifying the performance function which is normally chosen to be the sum of squares of the network errors on the training set defined as:

$$
M S E=\frac{1}{2} \sum_{P=1}^{n}\left(Y_{O}-Y_{P}\right)^{2}
$$

Where $Y_{o}$ is the actual value for the output while $Y_{p}$ is the predicted value. The modified performance function is defined by adding a term that consists of the mean of the sum of squares of the network weights and biases to the original Mean Square Error (MSE) function as:

$$
M S E_{\text {reg }}=\gamma \times M S E+(1-\gamma) \times M S W
$$

Where $\gamma$ is the performance ratio that takes values between 0 and 1; and MSW is computed as:

$$
M S W=\frac{1}{M} \sum_{j=1}^{M} w_{j}^{2}
$$

where $\mathbf{M}$ is the number of weights utilized inside the network structure and $w$ is weight matrix of the network.

On the other hand, the second method used in this study is the early stopping method. In general, the aim of early stopping is to mimic the prediction of future individuals from the 
population [Noureldin, 2011]. During the update stage (training), the module performs the function of understanding the input/output mapping as shown in Fig. 4. To ensure the generalization of the ANN model a hold out kind of early stopping procedure is used [Noureldin, 2011]. As depicted in Fig. 4, part of training data used by the early stopping criterion corresponds to the intermediate interval between the update (training) and testing stages. This approach allows ANN to readjust its parameters to detect the variance of the data in a transition interval before moving to the testing stage. Furthermore, it avoids the possibility of model overfitting for the training data.

\subsection{Ensemble Method}

In this method, we use a sequence of the previous behavior of the system as the training data. We then generate a sequence of inputs of proper length (with respect to the size of the best period in the previous section) and their corresponding outputs for the first $90 \%$ of 10 years (training data). Subsequently, we construct a series of networks with an initial guess for the number of neurons in the hidden layers and initialize their parameters randomly. Finally, for every network, the parameters vector will stop on a local minimum of its performance surface.

Up to this point, all of the networks are over-fitted on the training set. Therefore, a simulated annealing process is applied on each network. To do this, the model is modified to generate a set of noise vectors. The length of each noise vector is equal to the length of each network parameters vector (input). The noise vector is comprised of random numbers with uniform distribution between -0.05 and +0.05 . By adding noise vectors to the network parameter vectors (input), a new set of network parameters is obtained. This action makes relatively minor changes in the location of each network in its state space. The networks are trained with these noisy parameters until another local minimum is achieved. The process of making noise vectors 
and training is repeated many times, and the outputs of these networks are compared with the remaining $10 \%$ of the 10 years (which was not used during the training). The winning network, which is the one with the best generalization, is selected as the first member of an ensemble of neural networks.

In learning phase, a random vector of length $N$ is generated, where $N$ is the length of the sequence of the first 10 years of time-series values. This vector, called the data noise vector, is defined as:

$V_{d n}=M \times 10^{-2} \times z \times \operatorname{rand}(1, N)$

where $\mathrm{z}$ is the number of networks added to the ensemble of neural networks before this step, and $\operatorname{rand}(1, N)$ is a $1 \times N$ vector. The components of this vector are uniformly distributed random numbers between -0.05 and $+0.05 . \mathrm{M}$ is the difference between the maximum and minimum values of the time-series of the behavior of the system.

The number of neurons in the hidden layers of the networks is calculated using:

$$
\begin{aligned}
& n_{1}^{\prime}=\left|x \times \frac{n_{1}}{n_{2}}\right| \\
& n_{2}^{\prime}=x+n_{2}
\end{aligned}
$$

where $n_{1}$ and $n_{2}$ are the initial number of neurons in the first and second hidden layers of the first set of networks, respectively, and $n_{1}^{\prime}$ and $n_{2}^{\prime}$ are new values. The value of $x$ is obtained through:

$$
\begin{aligned}
& x=\left\{\frac{I N+1}{2} \mid \times \bmod ((I N-1), 2)\right\}- \\
& \left\{\left[\left|\frac{I N+1}{2}\right| \times\left|\frac{1+\operatorname{sign}\left(n_{2}-\left|\frac{I N+1}{2}\right|\right.}{2}\right|+\left(\left(2 \times n_{2}-\mid \frac{I N+1}{2}\right)-1\right) \times\left|\frac{1-\operatorname{sign}\left(n_{2}-\left|\frac{I N+1}{2}\right|\right.}{2}\right|+0.5\right] \times \bmod (I N, 2)\right\}
\end{aligned}
$$


where $I N$ is the iteration number. Following this initial step, if $I N$ is even, then the networks will be constructed with the previous structure but with more neurons. If $I N$ is odd, then the number of neurons will be decreased until a zero limit is met. This iteration enables us to find a more suitable number of neurons in the completion process of the ensemble, if the initial guess was not accurate and the networks need more (or less) neurons to achieve a good generalization.

After finding the best network in each set, we compute the sum of absolute errors in the prediction of the last $10 \%$ of data, using:

$e_{1}=\frac{\sum_{i=1}^{z} \sum_{j=1}^{k}\left|T_{s}(j)-\operatorname{Pr}(i, j)\right|}{z}$

$e_{2}=\frac{\sum_{i=1}^{z+1} \sum_{j=1}^{k}\left|T_{s}(j)-\operatorname{Pr}(i, j)\right|}{z+1}$

where $z$ is the number of networks that were added to the ensemble before this step; $T s$ is the sequence of the last $10 \%$ of events of time-series in the training dataset; and $k$ is the size of $T s$. $\operatorname{Pr}(i, j)$ is the value that the $i^{\text {th }}$ member of the ensemble predicts for the $j^{\text {th }}$ event in the last $10 \%$ of the time-series events. If $e_{1}$ is $>e_{2}$, then adding the best network of this step to the ensemble has improved the generalization of the overall ensemble. Otherwise, we do not add the selected network to the ensemble, and we repeat this step with new noisy datasets and a new set of networks with a different number of neurons in their hidden layers.

The terminating condition is as follows: a predefined number of iterations (namely $i_{\text {tr }}$ ) are considered. At the end of these iterations, the improvement of ensemble predictions (on the last $10 \%)$ is measured. If this value is smaller than a predefined factor, then the termination condition 
is met. Otherwise, the process is repeated. Figure 4 illustrates the learning phase for the proposed ENN model.

\subsection{Model performance}

There are various statistical indices that could be used to evaluate the performance of a certain model. To investigate model performance, we used the mean absolute relative error (MARE), mean absolute error (MAE), mean square error (MSE), and correlation coefficient $\left(\mathrm{R}^{2}\right)$. The first 3 parameters were calculated according to:

$$
\begin{aligned}
& \text { MARE }=\frac{1}{N} \sum \frac{\left|y-y^{\prime}\right|}{y} * 100 \\
& M A E=\frac{\sum\left|y-y^{\prime}\right|}{N} * 100 \\
& M S E=\frac{\sum\left(y-y^{\prime}\right)^{2}}{N}
\end{aligned}
$$

where $y$ is the $E T_{o}$ calculated by $\mathrm{PM}, y^{\prime}$ is the $E T_{o}$ predicted by the model, and $N$ is the total number of data points. $\mathrm{R}^{2}$ was determined by linear correlation between the actual and simulated data.

Because the prediction accuracy of the peak and low $E T_{o}$ events is of particular interest to reservoir operation, it is important to evaluate the model performance considering these inflow events. Therefore, the peak value criteria (PVC) and low value criteria (LVC) were used, defined as follows:

$$
P V C=\frac{\left(\sum_{i=1}^{T_{p}}\left(E T_{o m}-E T_{o p}\right)^{2} *\left(E T_{o m}\right)^{2}\right)^{0.25}}{\left(\sum_{i=1}^{T_{p}}\left(E T_{o m}\right)^{2}\right)^{0.5}}
$$


$L V C=\frac{\left(\sum_{i=1}^{T_{i}}\left(E T_{o m}-E T_{o p}\right)^{2} *\left(E T_{o m}\right)^{2}\right)^{0.25}}{\left(\sum_{i=1}^{T_{i}}\left(E T_{o m}\right)^{2}\right)^{0.5}}$

where $T_{p}$ is the number of peak flows greater than one-third of the mean peak $E T_{o}$ value observed, and $T_{i}$ is the number of $E T_{o}$ values that are less than one-third of the mean low flow observed. El-Shafie (2009) reported that both PVC and LVC provide good performance indicators of the forecasting model performance for extreme inflow events. As the model can provide low PVC or LVC as the model represents better fit.

\section{Results and Discussion}

\subsection{ANN without over-fitting procedure}

Different MLP-ANN architectures were used to examine the best performance, while keeping 3 neurons and 1 neuron in the input and output layers, respectively, according to the proposed scenarios. The selection of the number of hidden layers and the number of neurons in each layer was based on the RMS value of the prediction error for the training set as a performance index. Several trials of 1-layer FFBD were trained by different neurons and training functions to achieve the best results. In each process, the training was performed, and both simulations were evaluated down to lowest error and up to the highest regression coefficient. For the sake of consistency, careful supervision was applied to the training and both simulations. It was found that the use of more neurons led to better training results but worse testing and vice versa.

The adaptive value $m u$ is increased until the change shown above results in a reduced performance value. A change is then made to the network, and $m u$ is decreased. To achieve the 
best performance, a carefully supervised network was created by setting the $m u$, mи decrease, and $m u$ increase parameters to $1,0.8$, and 1.5, respectively. Figure 5 shows a sample performance plot obtained while training the network to reach the goal. A supervised training that was stopped at epoch 11 led to low error and consistency of the training in both simulations. The number of hidden layers $(\mathrm{R})$ and the number of neurons in each layer $(\mathrm{N})$ for each network are given in Table 1. The transfer functions used in each layer of the networks were also listed in Table 1.

\subsubsection{ANN model versus AR model}

After successfully training the networks, we performed the test and validation sessions, utilizing the data in years 1986 and 1987 for testing and in year 1988 for validation. Because the $E T_{o}$ values were accurately calculated with the PM method over the 1986-1987 period, the performance of the proposed ANN-based architecture can be examined and evaluated.

Moreover, to compare the ANN to existing modeling techniques, we compared the prediction error of the ANN with the prediction error from the auto-regressive moving average (ARMA) models. Table 2 shows the comparison of the performance of the ANN to the ARMA models using the maximum relative error (MaxRE\%) as shown in Eq. 11 and the correlation coefficient (Elshafie and Noureldin, 2011).indicator for each month. It is obvious from Table 2 that the ANN model outperformed the ARMA models with remarkable improvements in the correlation coefficient for both weekly and monthly basis.

\subsection{Evaluation of different Scenarios with ANN model}

Up to this point, the ANN modeling provides better accuracy level if compared with ARMA model. Consequently, in this stage, evaluation for different ANN model scenarios is required. 
For both scenarios I and II have been evaluated with respect to the model evaluation criterion as reported in section (4.6).

Table 3 and 4 show the results achieved while employing scenarios I and II, respectively, for all months in 1986, 1987 (testing dataset), and 1988 (validation dataset). In addition, tables 3 and 4 show the same complete details for selected statistical indices for the performances utilizing the HGS model. ANN provided a significant level of accuracy compared with HGS in both scenarios. In scenario I, the ANN model provided a high and consistent level of accuracy for all performance functions and regression coefficients for February and April for the testing and validation datasets. However, the other 2 months (July and December) showed lower accuracy levels for testing, with regression coefficients equal to 0.86 and 0.84 , respectively. The results achieved from scenario II in February and April are quite similar to those achieved in scenario I, although relative improvements were obtained for July and December. Generally, it could be noticed that scenario II showed better results over scenario I.

In the light of the above results, it was decided to perform scenario III (which consider the historical input records) based on scenario II architecture. For scenario III, different historical input pattern $\mathrm{P}$ (P equal to 1, 2 and 3) has been examined. Tables 5 and 6 show the statistical indices (MAE, MARE, MSE, and $\mathrm{R}^{2}$ ) as presented in section (4.6). If tables 5 and 6 deeply investigated, it could be observed that scenario III with $\mathrm{P}$ equal to 2 provides better results for all the statistical indices. In case $\mathrm{P}$ equal to 1 , the input parameters do not have enough temporal information that could achieve high level of accuracy for the output. In case $\mathrm{P}=3$, the input parameters will be 12 inputs which might lead to redundant in the input information that create more complexity in the model and make high possibility for increasing the error level in the model output. Furthermore, it was reported that many inputs in the ANN input layer affect 
negatively on the ANN model output accuracy, Bishop, 1995. It seems that when P equal to 2 might introduce the best temporal input pattern to the model thus achieve the best results if compared when $\mathrm{P}$ equal to 1 or 3.

In search of better understanding of the above observations, it could be noticed that the mean square error (MSE) is relatively high. Therefore, it becomes obvious that the ANN models experienced over-fitting and require further optimization to produce robust prediction with consistent error levels over all networks. The problem of non-consistent prediction is always related to over-fitting during learning (Ripley, 1996 and Haykin, 1999).

\subsection{ANN with over-fitting procedure}

The over-fitting procedures described in Sections 4.4 and 4.5 were applied to improve the generalization of the training process of the twelve networks in scenario III with P equal to 2 . In

order to examine each over-fitting procedures, the statistical indices (MAE, MARE, MSE, and R2) are evaluated over all months utilizing ANN without and with over-fitting procedure. An accuracy improvement (AI) index for each of the above statistical indices was employed to measure the significance of applying different over-fitting procedure, as follows:

$$
A I \%=\left(\frac{E_{\text {scenariolI }}-E_{\text {scenarionII }(O F P)}}{E_{\text {scenariolI }}}\right) * 100
$$

In Eqn. 24, $E_{\text {scenariolI }}$ is the value of the statistical error given by scenario III, while $E_{\text {scenarionII }(O F P)}$ is the same statistical error given by the proposed scenario III after applying different over-fitting procedure.

\subsubsection{Regularization}

For the regularized technique, a trial and error procedure is applied to determine the best $\gamma$ ratio that would regularize the model and overcome the over-fitting problems. Optimization 
techniques were not necessary as value of $\gamma$ easily converged by simplified trial and update procedures (Gelb, 1979). Different values of $\gamma$ ranging between 0 and 1 are examined for each network. The analysis showed that $\gamma$ ratio equals to 0.8 provided a considerable reduction in the error distributions of all twelve networks. Fig (8) demonstrates the AI\% "between the proposed ANN model and ANN with regularized procedure (see eq. 24)" performance indicator for $\mathrm{ET}_{\mathrm{o}}$ prediction for each month during the testing years (1986-87 and 1988). It can be observed that the regularized network improved for all statistical indices MAE, MARE and MSE.

\subsubsection{Early Stopping}

The early stopping criterion is applied utilizing input vectors from the $\mathrm{ET}_{\mathrm{o}}$ on which the ANN model was not trained. This input data is presented to the trained ANN model to examine its capability to accurately predict the corresponding output data. As shown earlier in Fig. 5, a

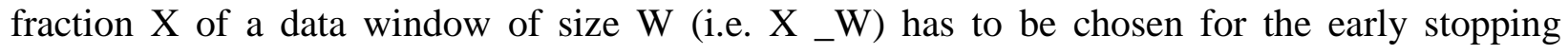
procedure. It is important to choose this part of the input data so that it is big enough to be representative of the existing features. We have, therefore, decided to examine the performance of the update procedure while choosing the size of the data record used by the early stopping criterion to be equal to one-tenth, one-fifth and two-fifth of the window size. After examined all size of fraction X, apparently, if two-fifth of data was used by the early stopping criterion, the ANN was not well trained and thus the error level was relatively high. The main reason for this is that there was not enough data record for the training process, which made it difficult to reach the error goal. On the other hand, when one-tenth of the data was used, relatively short data for the early stopping criterion to function appropriately is experienced. As a result almost same level of accuracy as utilizing the ANN model without over-fitting procedure was observed. Therefore, it was decided to select the percentage $\mathrm{X}$ of the data set for early stopping to be one- 
fifth of the training data. This choice gave the training procedure enough data to be create the ANN model. It also gave enough data record for the early stopping criterion to function. The performance of the early stopping using fraction $\mathrm{X}$ equal to one-fifth of the training data is demonstrated in figure 9 showing that the $\mathrm{AI} \%$ for the entire statistical index "between the proposed ANN model and the ANN with early stopping procedure". It could be depicted that the early stopping procedure outperformed the regularized procedure.

\subsubsection{Ensemble Procedure}

The ensemble procedure has been performed to improve the generalization of the training process of the 12 networks with scenario III $(\mathrm{P}=2)$. For example, the ENN model was applied for the same 2 months (July and December) that experienced relatively poor accuracy for the testing and validation datasets because of the problem of over-fitting while training. Figure 10 shows that 7 and 8 networks were selected, respectively, as ensemble members for July and December before the termination conditions were met. The MSE calculated here was associated with the last $10 \%$ of the training dataset between 1975 and 1985 . On the other hand, for all the other months, it could be noticed that 4 networks as ensemble members were enough to reach the termination conditions for MSE index.

Figure 11 illustrates the AI\% for all the statistical indices for the 12 months. Overall, the ANN model with ensemble procedure provided better results for all months for all statistical indices compared with regularized and early stopping procedures as presented in figures 8 and 9 .

For further assessment, the ENN model for scenario III $(\mathrm{P}=2)$ was examined for the peak and low ET $T_{o}$ events. The PVC and LVC statistics, as discussed in section 4.6 and presented in Eqs. 22 and 23, are presented in Table 7. The ENN model provided an accurate prediction value for the PVC, ranging $1.45 \%$ to $5.3 \%$ for January and July, respectively. The LVC values 
experienced better prediction error compared with the PVC, with LVC values ranging $1.2 \%$ to 5\% for November and March, respectively. The PVC and LVC values achieved with the classical ANN model were higher than those obtained with the ENN model, ranging $2.2 \%$ to 9.53\% for PVC and $1.25 \%$ to $5.84 \%$ for LVC for January, August, November, and September. Thus, the proposed ENN model outperformed the classical ANN model, and its utilization improved the prediction error for both medium and extreme $E T_{o}$ values.

Finally, multi-lead prediction for $\mathrm{ET}_{\mathrm{o}}$ has been examined utilizing the ANN model scenario III $(\mathrm{P}=2)$ with ensemble procedure. In fact, such predictions skill for the ANN model could not be afforded by the traditional HGS model, thus, in general, this is considered as major advantage of the proposed ANN. In order to perform such task for multi-lead prediction, two different approaches have been carried out. The first approach is to add the predicted value of $\mathrm{ET}_{\mathrm{o}}(\mathrm{t}+1)$ to the input parameters even it has certain level of error to predict the value of $\mathrm{ET}_{\mathrm{o}}(\mathrm{t}+2)$. Consequently, to predict the value of $\mathrm{ET}_{\mathrm{o}}(\mathrm{t}+3)$, to add the predicted value of $\mathrm{ET}_{\mathrm{o}}(\mathrm{t}+2)$ to the same input parameters to predict the value of $\mathrm{ET}_{\mathrm{o}}(\mathrm{t}+3)$. While the second approach is to use the same input parameters (scenario III $(\mathrm{P}=2)$ ) to predict the value of $\mathrm{ET}_{\mathrm{o}}$ at $(\mathrm{t}+2)$ and $(\mathrm{t}+3)$, in other word, is to rely only on the actual values for all input parameters. Table 8 shows performance of the multi-lead prediction for the two days ahead, $(\mathrm{L}=2$ and $\mathrm{L}=3)$ for the year 1988 using Average Prediction Error (MSE) as presented in Eq.(21).

Where $\mathrm{N}$ is the number of days within this month, $E T_{o}(a)$ is the $\mathrm{ET}_{\mathrm{o}}$ value as calculated with the FAO $E T_{o}$ calculator (version 3.1 January 2009), while $E T_{o}(p)$ is the predicted value as output from the proposed model. For the first approach, the second column corresponds to the case when one predicted $\mathrm{ET}_{\mathrm{o}}$ is used as network inputs, while the third column corresponds to 
the case when two predicted $\mathrm{ET}_{\mathrm{o}}$ is utilized. The followed fourth and fifth columns are associated to the results when applying the second approach.

Generally, for both approaches, it can be observed that the accuracy is reduced when L (Multi-Lead length) is increased, as presented in Table 8. For example, the MSE for the ETo predicted at the month of November was 0.018 using the actual input data (second approach) with respect to scenario III $(\mathrm{P}=2)$ as multi-lead ahead $(\mathrm{L}=2)$, then again, MSE increased to be 0.034 when November considered as third Multi-Lead ahead $(\mathrm{L}=3)$. On the other hand, when utilizing the first approach, the MSE for November is 0.022 and 0.044 for second and third multi-lead (L equal to 2 and 3), respectively. Such observations could be noticed for all months except months of May, June, July and August, it could be depicted that the MSE for those months are $0.069,0.164,0.184$ and 0.152 for $\mathrm{L}=2$, respectively. This is due to the fact that these months are considered as the dry period and might experienced slow decay in the crosscorrelation with the previous input data. This is confirm that, for multi-lead prediction, it might be better to utilize the predicted values with certain level of error but highly correlated with the output as a predictor rather than utilizing actual values which are not correlated and higher order with the output.

Compared with the results reported in the previous research, Khoob (2007) developed a neural network method in order to estimating monthly ETo at Khuzestan plain, located in the southwest of Iran. In this study, the maximum and minimum air temperatures $\left({ }^{\circ} \mathrm{C}\right)$ and the extraterrestrial radiation (mm day-1) were adopted as input variables for the ANN. The developed model it gave $\underline{\text { reliable estimation in this study. However, regardless of the results that obtained, some definite }}$ problems such as over-fitting can occur especially when number of nodes in the hidden layer is determined by trial and error. (Reuter and Möller, 2010; Graf et al, 2010; Daniel et al, 2010) 
Therefore, in order to avoid an over-fitting problem, several over-fitting procedures have been augmented with the classical ANN model, are proposed in this research, The number of nodes in the hidden layer was determined by trial and error.

\section{Conclusion}

This study introduced a procedure for the development of an ANN model for predicting monthly time-series $E T_{o}$ data using only maximum and minimum temperatures and solar radiation. In addition, this study introduced ARMA model for the same application. Comparison analysis have been developed between the proposed ANN model and ARMA model, in addition, the proposed ANN model was evaluated and compared with the traditional HGS model. Furthermore, three different scenarios were employed for the input-output pattern of the ANN model architecture to optimize the accuracy level. Several over-fitting procedures were applied to overcome the over-fitting problem that was experienced while training the ANN model.

The classical ANN model outperformed the ARMA and HGS models and achieved reliable performances, including low MAE, MARE, and MSE and high $\mathrm{R}^{2}$ results. Moreover, the results show that including the temporal pattern in the ANN model is essential to be considered in order to enhance the accuracy level. In addition, the proposed ensemble procedure for ANN model showed significant enhancement over the classical ANN model, proving its reliability and consistently high accuracy, when predicting the extreme values of $E T_{o}$ and outperformed the other over-fitting procedures; namely; regularization and early stopping. Finally, the proposed ANN model with the ensemble procedure could provide acceptable level of accuracy for multilead predictions skill. Nevertheless, due to the fact that evapotranspiration forecast can be easily affected by external environment, the obtained model sometimes produced results that were 
much deviated from the actual values; therefore, further research needs to be done in future work to identify the suitable forecast model, understand its laws of changes, and solve the problem of forecast deviation. In general, this research work has managed to integrate several analytical and modelling methods that would prove to be useful for various institutions that are directly involved in the management of the hydrology. Moreover, the tools used in this work could form a basis for a more effective decision making process on the part of the policy makers in order to help maintain and improve the management of hydrology. In addition, attention to the use of a temperature based approach for estimating RS introduces considerable uncertainty in the use of the PMF-56 method as it might experience considerable level of uncertainty in the empirical adjustment factor, hence, affecting the accuracy of the model.

\section{Acknowledgements}

This research is supported by a research grants to the first author by Smart Engineering System, and Water and Environmental Research Group, University Kebangsaan Malaysia; UKM-GUP2011-034, UKM-DLP-2011-002 and FRGS/1/2012/TK03/UKM/02/4. 


\section{References}

Adeli, H. and Hung, S. L. (1995), Machine Learning - Neural Networks, Genetic Algorithms, and Fuzzy Systems, John Wiley \& Sons, New York.

Adeli, H. and Vishnubhotla, P. R. (1992), Parallel processing and parallel machines, in Adeli, H. (ed.), Parallel Processing in Computational Mechanics, Marcel Dekker, New York, pp. 1-20.

Ahmadreza Zamani, Arnold Heemink and Dimitri Solomatine, 2009 Wave height prediction at the Caspian Sea using a data driven model and ensemble-based data assimilation methods, journal of Hydroinformatics, $11.2 \mathrm{pp} 154-164$

Alexandra P. Jacquin and Asaad Y. Shamseldin, 2009, Review of the application of fuzzy inference systems in river flow forecasting, journal of Hydroinformatics, 11.3-4 pp 202-210

Allen, R. G., Pereira, L. S., Raes, D., and Smith, M. (1998). "Crop evapotranspiration: Guidelines for computing crop water requirements."FAO Irrigation and Drainage Paper 56, Food and Agricultural Organization of the United Nations (FAO), Rome. Artificial Neural Network. J Irrg Drain Eng 129(6):454-457

Awchi T., A. (2007). "Application of Radial Basis Function Neural Networks for Reference Evapotranspiration Prediction."Al-Rafidain Engineering Vol.16.

Birkinshaw S. J., G. Parkin and Z. Rao, 2008, A hybrid neural networks and numerical models approach for predicting groundwater abstraction impacts, journal of Hydroinformatics, $10.2 \mathrm{pp}$ $127-137$ 
Chauhan, S. and R. K. Shrivastava (2008). "Performance Evaluation of Reference Evapotranspiration Estimation Using Climate Based Methods and Artificial Neural Networks." Water Resources Management 23: 825-837.

Chowdhury, S. and A. Sharma (2009). "Multisite seasonal forecast of arid river flows using a dynamic model combination approach" Water Resources Research 45(10): art. no. W10428

Clair, T. A., and Ehrman, J. M. (1998). "Using neural networks to assess the influence of changing seasonal climates in modifying discharge, dissolved organic carbon, and nitrogen export in eastern Canadian rivers.'” Water Resour. Res., 34(3), 447-455.

Coulibaly, P., Anctil, F., and Bobee, B. (2000).'Daily reservoir inflow forecasting using artificial neural networks with stopped training approach. '’J. Hydrol., 230(3-4), 244-257.

Daniel Boto-Giralda, Francisco J. Díaz-Pernas, David González-Ortega, José F. Díez-Higuera, Míriam Antón-Rodríguez, Mario Martínez-Zarzuela and Isabel Torre-Díez, 2010, WaveletBased Denoising for Traffic Volume Time Series Forecasting with Self-Organizing Neural Networks, Computer-Aided Civil and Infrastructure Engineering, 25(7): 530-545,

Drucker, H., Cortes, C., Jackel, D., 1994 “Boosting And Other Ensemble Methods”. Neural Computation, Vol. 6, Pp. 1289-1301.

El-Shafie Ahmed, Alaa E. Abdin, Aboelmagd Noureldin And Mohd R. Taha, 2009 "Enhancing Inflow Forecasting Model At Aswan High Dam Utilizing Radial Basis Neural Network And Upstream Monitoring Stations Measurements” Water Resources Management, Springer, 23( 11) Pp. 2289-2315. 
El-Shafie, A.H., El-Shafie, A., El Mazoghi, H.G., Shehata, A., Taha, M.R. 2011 Artificial neural network technique for rainfall forecasting applied to Alexandria, Egypt, International Journal of Physical Sciences 6 (6), pp. 1306-1316

Elshorbagy, A., Simonovic, S. P., and Panu, U. S. (2000).“Performance evaluation of artificial neural networks for runoff prediction '’J. Hydrologic Eng., 5(4), 424-427.

Fernando, D. A., and Jayawardena, A. W. (1998). “'Runoff forecasting using RBF networks with OLS algorithm .'J. Hydrologic Eng., 3(3),203-209.

Fooladmand HR (2011) Evaluation of some equations for estimating evapotranspiration in the $\underline{\text { south of Iran. Arch Agron Soil Sci 57(7):741-752 }}$

Ge Gao, Chong-Yu Xu, Deliang Chen and V. P. Singh, (2012) Spatial and temporal characteristics of actual evapotranspiration over Haihe River basin in China, Stoch Environ Res Risk Assess 26:655-669

Giustolisi, O. And Simeone, v. (2006): Optimal design of artificial neural networks by a multiobjective strategy: groundwater level predictions, Hydrological Sciences Journal, 51:3, 502-523

Giustolisi, O. and Laucelli, D. (2005): Improving generalization of artificial neural networks in rainfall-runoff modelling / Amélioration de la généralisation de réseaux de neurones artificiels pour la modélisation pluiedébit, Hydrological Sciences Journal, 50:3, -457

Graf W., S. Freitag, M. Kaliske and J.-U. Sickert, 2010, Recurrent Neural Networks for Uncertain Time-Dependent Structural Behavior, Computer-Aided Civil and Infrastructure Engineering, 25(5): 322-323, 
Hargreaves GH, Samani ZA (1985) Reference crop evapotranspiration from temperature. Application Engineering Agriculture 1(2):96-99

Hsu, K., Gupta, H. V., and Sorooshian, S. (1995). “Artificial neural network modeling of the rainfall-runoff process. 'Water Resour. Res.,31(10), 2517-2530.

Ioannis K. Tsanis, Paulin Coulibaly and Ioannis N. Daliakopoulos , 2008, Improving groundwater level forecasting with a feedforward neural network and linearly regressed projected precipitation, journal of Hydroinformatics, 10.4 pp 317-330

IPCC 2007 Summary for Policymakers, in: Climate Change 2007, Solomon, S., D. Qin, M.

Jain, S. K., Das, A., and Srivastava, D. K. (1999).“'Application of ANN for reservoir inflow prediction and operation.'J. Water Resour. Plan.Manage.,125(5), 263-271.

Jain, S. K., P. C. Nayak and K. P. Sudheer (2008).“Models for estimating evapotranspiration using artificial neural networks, and their physical interpretation."HYDROLOGICAL PROCESSES22 (13): 2225-2234.

Johnson, F. and A. Sharma (2010). "A Comparison of Australian Open Water Body Evaporation Trends for Current and Future Climates Estimated from Class A Evaporation Pans and General Circulation Models." Journal of Hydrometeorology 11(1): 105-121.

Khoob, A.R., (2008). “Comparative study of Hargreaves's and artificial neural network's methodologies in estimating reference evapotranspiration in a semiarid environment" Irrigation Science 26 (3), 253-259.

Kisi, O. (2009). "Modeling monthly evaporation using two different neural computing techniques."Irrigation Science27: 417-430. 
Kumar, M., Raghuwanshi, N. S., Singh, R., Wallender, W. W., and Pruitt,W. O. (2002).“Estimating evapotranspiration using artificial neuralnetwork.’J. Irrig. Drain. Eng., 128(4), 224-233.

L. Telesca, S. M. Vicente-Serrano and J. I. Lo'pez-Moreno (2012) Power spectral characteristics of drought indices in the Ebro river basin at different temporal scales Stoch Environ Res Risk Assess DOI 10.1007/s00477-012-0651-4

Liong, S. Y., Khu, S. T., and Chan, W. T. (2001). "Derivation of Pareto front with genetic algorithm and neural network.'’J. Hydrologic Eng.,6(1), 52-61.

Maier, H. R., and Dandy, G. C. (1999). “Empirical comparison of various methods for training feed-forward neural networks for salinity forecasting.' 'Water Resour. Res., 35(8), 2591-2596.

Marti P., A. Royuela, J. Manzano and G. Palau, "Improvement of Temperature Based ANN Models for ETo Prediction in Coastal Locations by Means of Preliminary Models and Exogenous Data,” his, pp.344-349, 2008 Eighth International Conference on Hybrid Intelligent Systems, 2008

Moghaddas Tafreshi, S.N., Tavakoli Mehrjardi, G. (2008). The Use of Neural Network to Predict the Behavior of Small Plastic Pipes Embedded in Reinforced Sand and Surface Settlement under Repeated-Load. Engineering Applications of Artificial Intelligence, Elsevier, 21 (6), 883894.

Mohammad Rezania, M., Faramarzi, A., A. Javadi, A., 2011. An evolutionary based approach for assessment of earthquake-induced soil liquefaction and lateral displacement. Engineering Applications of Artificial Intelligence, Volume 24, Issue 1, February 2011, Pages 142-153 
Nataliya Bulygina and Hoshin Gupta (2010)How Bayesian data assimilation can be used to estimate the mathematical structure of a model Stoch Environ Res Risk Assess 24:925-937

Noureldin, A., El-Shafie, A., Bayoumi, M. 2011 GPS/INS integration utilizing dynamic neural networks for vehicular navigation, Information Fusion 12 (1), pp. 48-57

Odhiambo, L. O., Yoder, R. E., and Hines, J. W. (2001). "Optimization of fuzzy evapotranspiration model through neural training with input-output examples." Trans. ASAE, 44(6), 1625-1633.

Qiang Zhang, Chong-Yu Xu, Yongqin David Chen and Liliang Ren (2011) Comparison of evapotranspiration variations between the Yellow River and Pearl River basin, China Stoch Environ Res Risk Assess 25:139-150

Rahimi Khoob, A (2008), Comparative study of Hargreaves's and artificial neural network's methodologies in estimating reference evapotranspiration in a semiarid environment. Irrig Sci 26(3):253-259

Rahimi Khoob, A., Behbahani M.B., Fakheri J. (2012) An Evaluation of Four Reference Evapotranspiration Models in a Subtropical Climate. Water Resources Management 26(10): $\underline{2867-2881 .}$

Razzaghi F, Sepaskhah AR (2010) Assessment of nine different equations for ETo estimation using lysimeter data in a semi-arid environment. Arch Agron Soil Sci 56(1):1-12

Reuter U. and B. Möller, 2010, Artificial Neural Networks for Forecasting of Fuzzy Time Series, Computer-Aided Civil and Infrastructure Engineering, 25(5): 363-374, 
Sabziparvar, A. A., Tabari, H. (2010) "Regional estimation of reference evapotranspiration in arid and semi-arid regions". Journal of Irrigation and Drainage Engineering ASCE 136(10):724$\underline{731}$

Samant, A. and Adeli, H. (2000), Feature extraction for traffic incident detection using wavelet transform and linear discriminant analysis, Computer-Aided Civil and Infrastructure Engineering, 15(4), 241-250.

Sudheer, K. P., A. K. Gosain and K. S. Ramasastri (2003).“Estimating Actual Evapotranspiration from Limited Climatic Data Using Neural Computing Technique.’Journal Of Irrigation And Drainage Engineering, 129(3): 214-218.

Surajit Chattopadhyay and Goutami Chattopadhyay, 2008, Identification of the best hidden layer size for three layered neural net in predicting monsoon rainfall in India, , journal of Hydroinformatics, 10.2 pp 181-188

Tabari H., Martinez, C., Ezani, A., Hosseinzadeh Talaee, P. (2012) "Applicability of support vector machines and adaptive neurofuzzy inference system for potato crop evapotranspiration forecasting". Irrigation Science doi: 10.1007/s00271-012-0332-6

Tabari, H. (2010) "Evaluation of reference crop evapotranspiration equations in various climates". Water Resources Management 24:2311-2337

Tabari, H., Grismer, M. E., Trajkovic, S. (2011) "Comparative analysis of 31 reference evapotranspiration methods under humid conditions". Irrigation Science doi: 10.1007/s00271011-0295 
Tabari, H., Hosseinzadeh Talaee, P. (2012) "Multilayer Perceptron for Reference Evapotranspiration Estimation in a Semiarid Region". Neural Computing \& Applications doi: $\underline{10.1007 / \mathrm{s} 00521-012-0904-7}$

Tao Yang, Xi Chen, Chong-Yu Xu and Zhi-Cai Zhang (2009) Spatio-temporal changes of hydrological processes and underlying driving forces in Guizhou region, Southwest China Stoch Environ Res Risk Assess 23:1071-1087

Todorovic, B., Stankovic, M., and Todorovic-Zakula, S. (2000). "Structurally adaptive RBF network in nonstationary time series prediction.'’Proc., Adaptive Systems for Signal Processing, Communication and Control Symposium, IEEE, New York, 224-229.

Tokar, A. S., and Johnson, P. A. (1999). "Rainfall-runoff modeling using artificial neural networks.'’J. Hydrologic Eng., 4(3), 232-239.

Trajkovic S, Todorovic B, and Stankovic M (2003) Forecasting of reference evapotranspiration by Artificial neural network for modeling reference evapotranspiration complex process in Sudano-Sahelianzone."Agricultural Water Management, 97(5): 707-714.

Wang, Y. M. and T. Kerh (2008)."Neural network approach for estimating reference evapotranspiration from limited climatic data in Burkina Faso.WSEAS Transactions On Computers, 7(6): 704-713.

Yonas B. Dibike and Paulin Coulibaly, 2008, TDNN with logical values for hydrologic modeling in a cold and snowy climate, journal of Hydroinformatics, 10.4 pp 289-300 
Zanetti, S. S., E. F. Sousa, V. P. S. Oliveira, F. T. Almeida and S. Bernardo (2007)."Estimating Evapotranspiration Using Artificial Neural Network and Minimum Climatological Data."Journal of Irrigation and Drainage Engineering133(2): 83-89. 
List of Figures
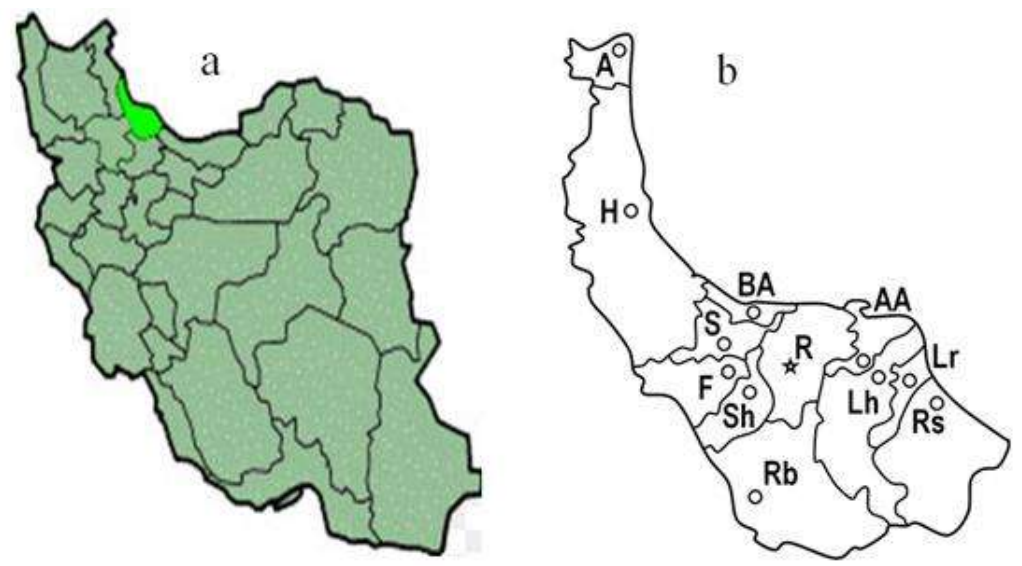

Figure 1 a) location of Gilan province in Iran b) Administrative Divisions of Gilan Province $\mathrm{R}=$ Rasht City

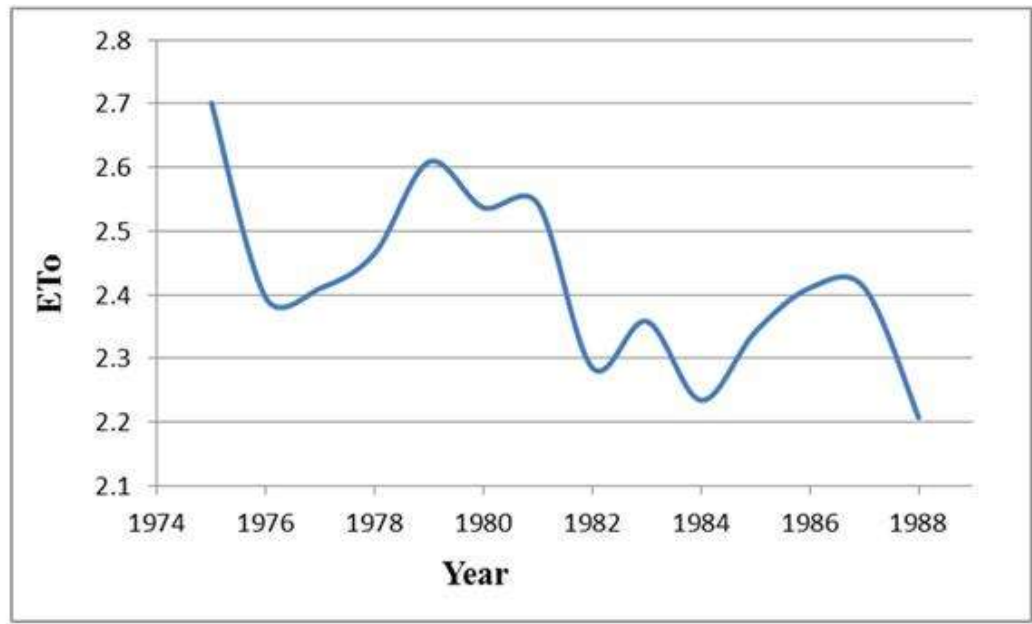

Figure 2 Annual mean ET calculated by PM method for the period of 1975 to 1988 


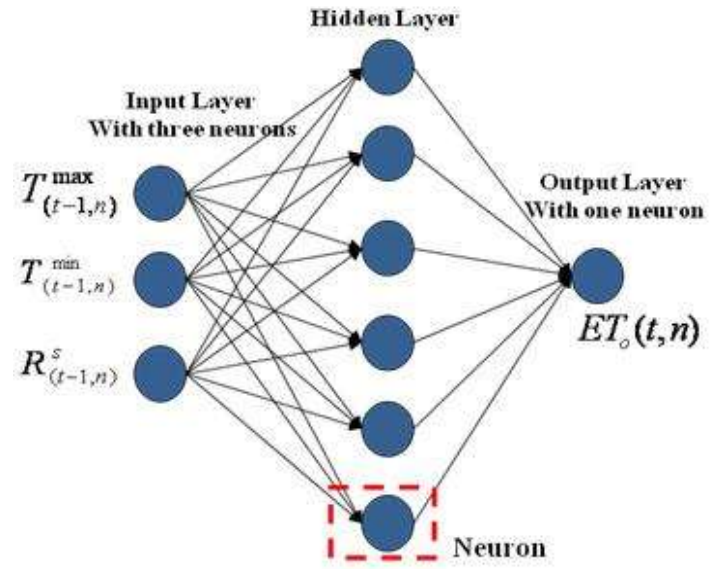

a) Scenario I

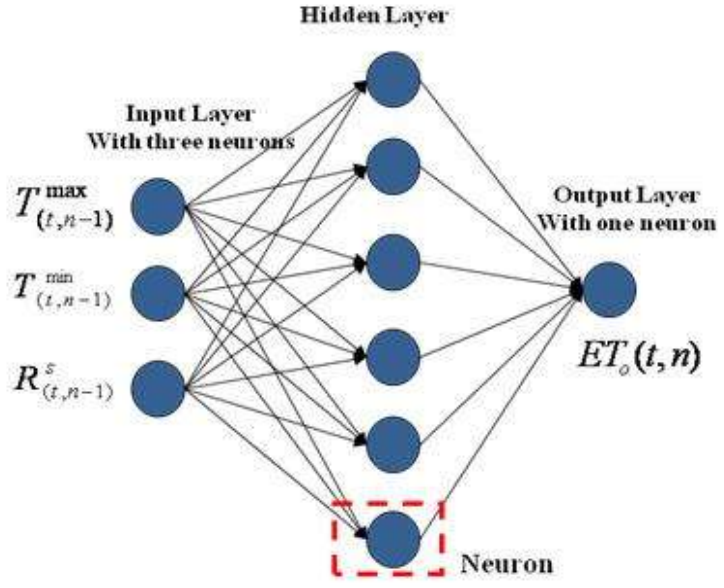

b) Scenario II

Figure 3 Exact architecture of the $\mathrm{ANN}$ for the proposed two scenarios a) scenario I b) scenario II

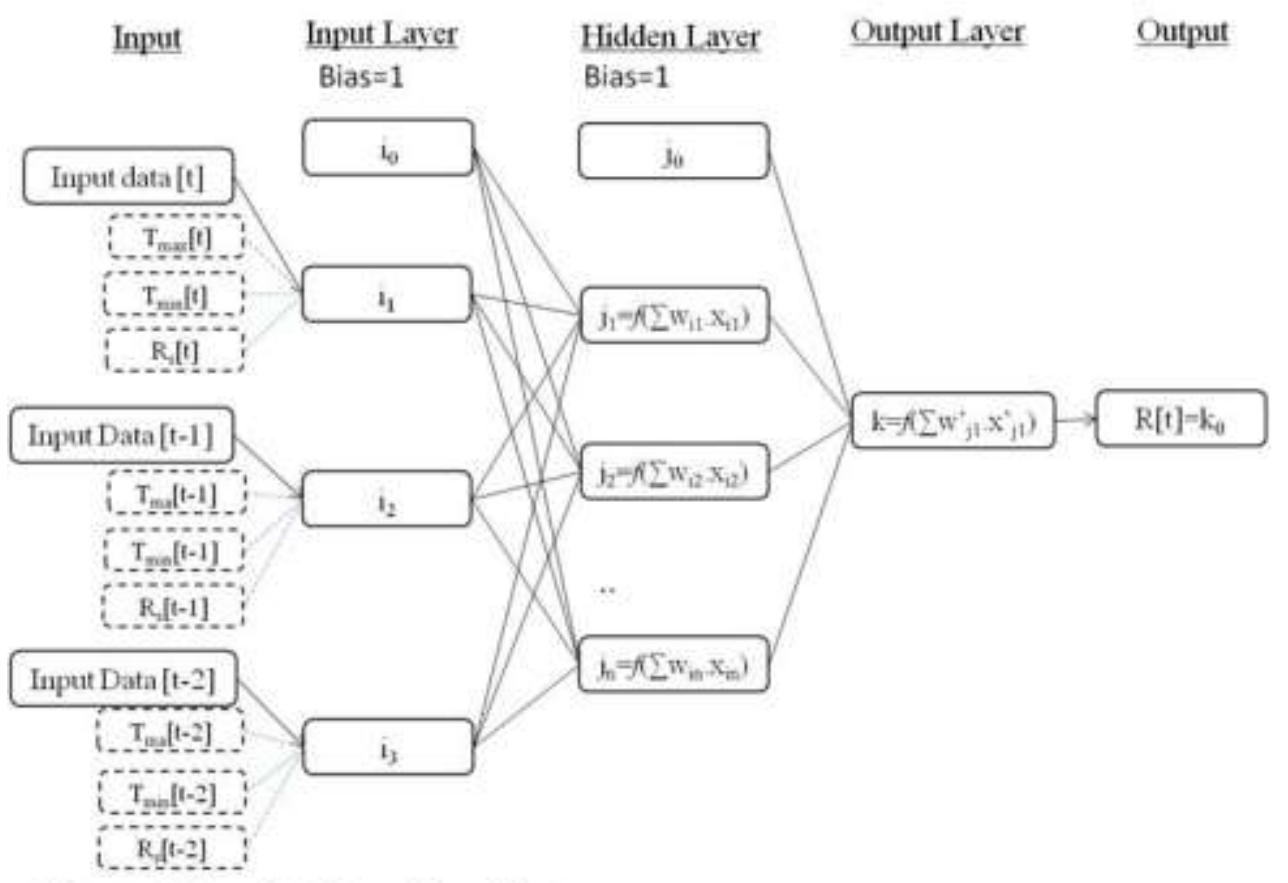

Figure 4 Scenario III model architecture 


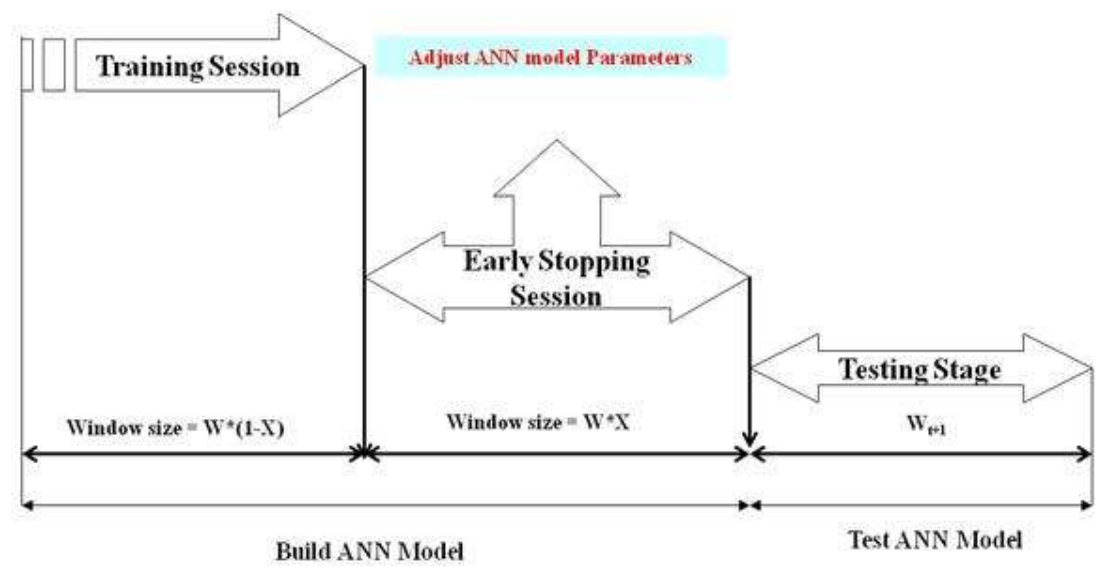

Figure 5. Time line index for the model'stages sequences

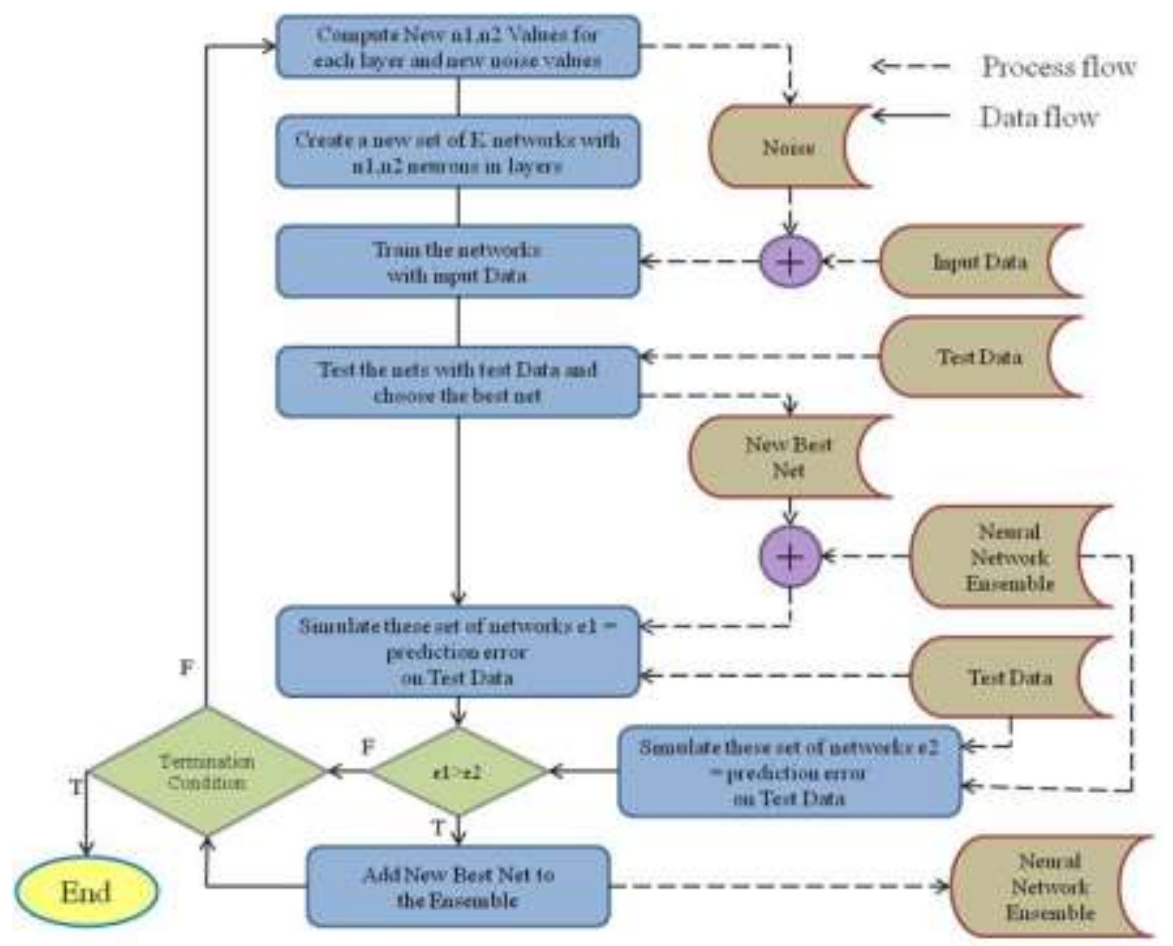

Figure 6 Learning Phase Process for Ensemble Neural network 


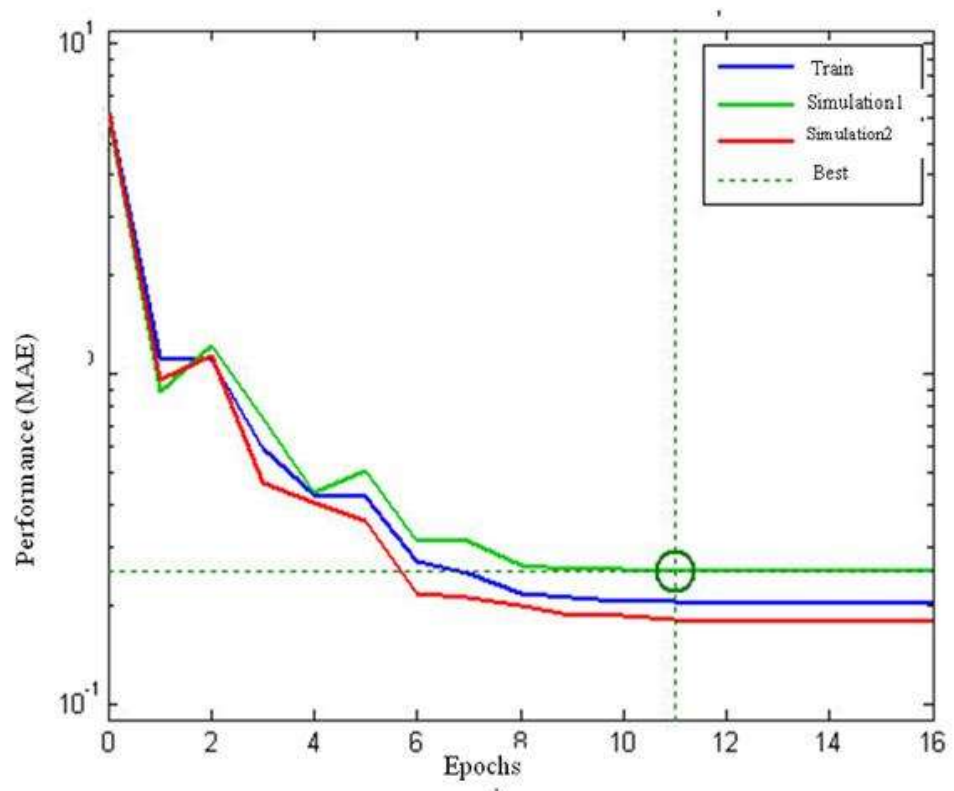

Figure $7 \mathrm{~A}$ sample of performance trend during training

A)
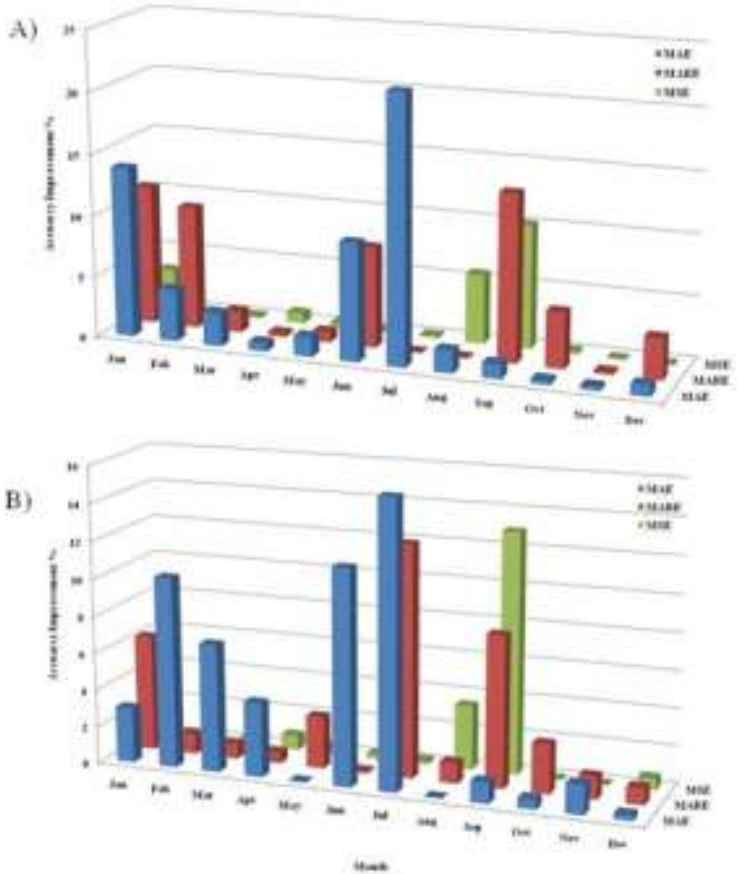

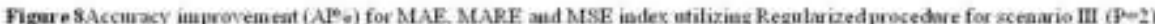
A) for the year 1986-87 aid B) for the year 1988 
A)

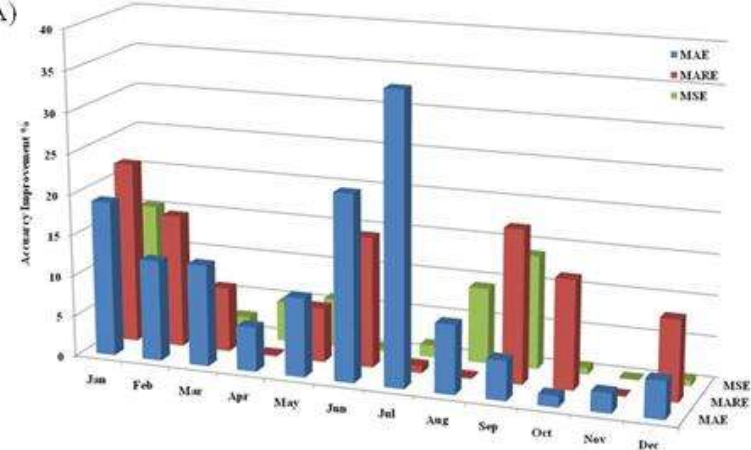

B)

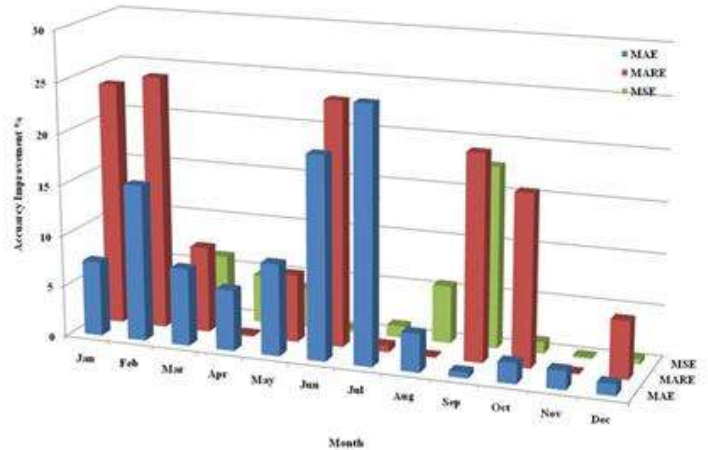

Figure 9Accuracy improvement ( $\mathrm{AI} \%$ ) for MAE, MARE and MSE index utilizing Early Stopping procedure for scenario III ( $\mathrm{P}=2$ ) A) for the year 1986-87 and B) for the year 1988

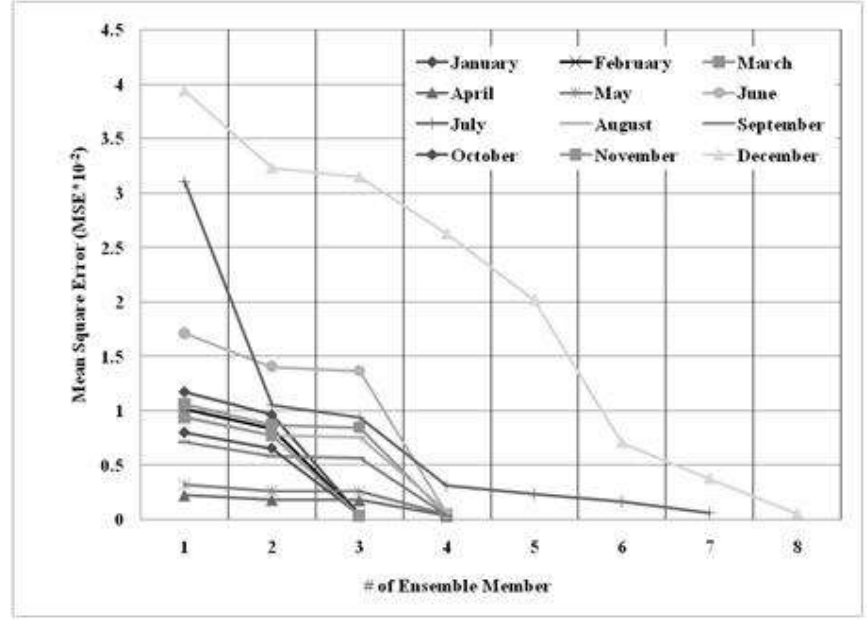

Figure 10 The effect of increasing number of ensemble neural network on the mean square error for months. July and December 
A)

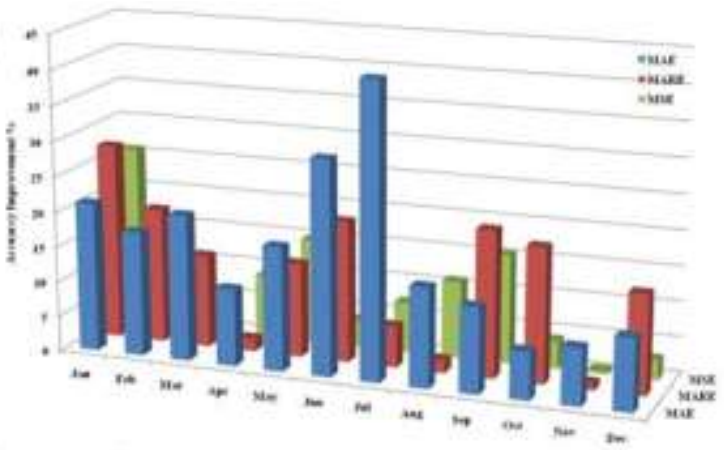

B)

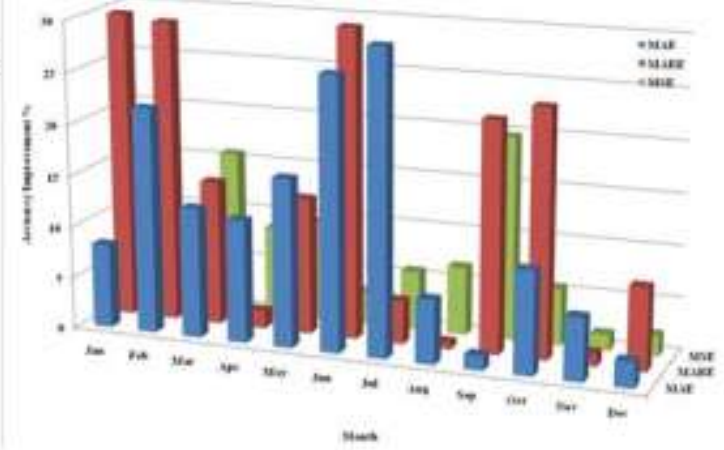

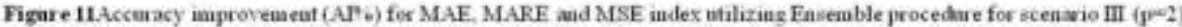
A) for the year $1986-87$ and B) for the year 1988 


\section{List of Table}

Table 1. The ANN architecture for each month for all scenarios

\begin{tabular}{|c|c|c|c|c|c|c|c|c|c|}
\hline & \multicolumn{4}{|c|}{ Scenario I } & \multicolumn{4}{c|}{ Scenanio II } & \multicolumn{3}{c|}{ Scenario III } \\
\hline Month & N & $\begin{array}{c}\text { Transfer } \\
\text { Function }\end{array}$ & $\begin{array}{c}\text { Transfer } \\
\text { function }\end{array}$ & N & $\begin{array}{c}\text { Transfer } \\
\text { Function }\end{array}$ & $\begin{array}{c}\text { Transfer } \\
\text { function }\end{array}$ & N & $\begin{array}{c}\text { Transfer } \\
\text { Function }\end{array}$ & $\begin{array}{c}\text { Transfer } \\
\text { function }\end{array}$ \\
\hline Jan & 6 & TS & PL & 6 & TS & PL & 5 & TS & PL \\
\hline Feb & 6 & TS & PL & 5 & TS & PL & 4 & TS & PL \\
\hline Mar & 5 & LS & PL & 6 & LS & PL & 6 & LS & PL \\
\hline Apr & 5 & LS & PL & 4 & LS & PL & 4 & LS & PL \\
\hline May & 6 & TS & PL & 5 & TS & PL & 5 & TS & PL \\
\hline Jun & 6 & TS & PL & 4 & TS & PL & 4 & LS & PL \\
\hline Jut & 4 & TS & PL & 4 & TS & PL & 5 & LS & PL \\
\hline Aug & 4 & TS & PL & 4 & TS & PL & 5 & TS & PL \\
\hline Sep & 6 & LS & PL & 5 & LS & PL & 5 & TS & PL \\
\hline Oct & 6 & LS & PL & 6 & LS & PL & 3 & TS & PL \\
\hline Nov & 5 & TS & PL & 6 & TS & PL & 5 & TS & PL \\
\hline Dec & 5 & TS & PL & 4 & TS & PL & 5 & TS & PL \\
\hline
\end{tabular}

$N(i)$ number of neuron in the Hidden layer (i)

LS: LS

TS: Tan_sigmoid

$\mathrm{PL}: \mathrm{PL}$

Table 2 Comparison of MAE, MARE, MSE and $\mathrm{R}^{2}$ between ARMA and the ANN scenario I

\begin{tabular}{|c|c|c|c|c|c|c|c|c|c|c|c|c|c|c|c|c|}
\hline \multirow{3}{*}{ Month } & \multicolumn{8}{|c|}{ ARMA } & \multicolumn{8}{|c|}{ ANNScethario I } \\
\hline & \multicolumn{2}{|c|}{ MAE } & \multicolumn{2}{|c|}{ MARE } & \multicolumn{2}{|c|}{ MASE } & \multicolumn{2}{|c|}{$\mathbf{R}^{2}$} & \multicolumn{2}{|c|}{ MLE } & \multicolumn{2}{|c|}{ MLARE } & \multicolumn{2}{|c|}{ MSE } & \multicolumn{2}{|c|}{$\mathrm{R}^{2}$} \\
\hline & $1986-87$ & 1958 & 1956.87 & 1958 & $1986-87$ & 1958 & 1986.87 & 1958 & 1986.87 & 195s & $1956-87$ & $198 s$ & 1986.87 & 1958 & 1986.87 & 1958 \\
\hline Jan & 0.14 & 0.15 & 15.38 & 16.34 & 0.04 & 0.04 & 0.76 & 0.74 & 0.13 & 0.14 & 13.98 & 14.86 & 0.03 & 0.04 & 0.95 & 0.93 \\
\hline Feb & 0.13 & 0.14 & 11.54 & 12.51 & 0.93 & 0.04 & 0.76 & 0.76 & 0.11 & 0.13 & 10.50 & 11.37 & 0.03 & e.03 & 0.96 & 0.94 \\
\hline Mar & 0.13 & 0.14 & 9.50 & 11.65 & 0.03 & 0.03 & 0.70 & 0.70 & 0.12 & 0.12 & 8.91 & 10.59 & 0.02 & 0.03 & 0.ss & e.s: \\
\hline Apr & 0.17 & 0.15 & 6.75 & 6.11 & 0.05 & 0.03 & 0.76 & 0.73 & 0.16 & 0.14 & 6.14 & 5.55 & 0.05 & 0.03 & 0.95 & 0.91 \\
\hline May & 0.23 & 0.27 & 6.68 & 8.28 & 0.08 & 0.11 & 0.75 & 0.72 & 0.21 & 0.24 & $6.0^{-}$ & 7.52 & 0.07 & 0.10 & 0.94 & 0.90 \\
\hline $\operatorname{San}$ & 0.20 & 0.27 & 5.29 & 6.15 & 0.05 & 0.09 & 0.75 & 0.69 & 0.19 & 0.24 & 4.81 & 5.59 & 0.05 & 0.09 & 0.94 & 0.56 \\
\hline$J \mathbf{u l}$ & 0.26 & 0.31 & 6.23 & s.03 & 0.09 & 0.11 & 0.69 & 0.69 & 0.24 & $0.2 \mathrm{~s}$ & 5.66 & 7.30 & 0.09 & 0.10 & 0.86 & 0.86 \\
\hline Ang & 0.28 & 0.28 & 7.57 & 9.45 & 0.12 & 0.11 & 0.69 & 0.69 & 0.25 & 0.26 & 6.58 & 8.59 & 0.11 & 6.10 & 0.86 & 0.86 \\
\hline Sep & 0.21 & 0.25 & 7.45 & 10.73 & 0.07 & 0.97 & 0.76 & 0.73 & 0.19 & 0.23 & $6.7 \mathrm{~s}$ & 9.96 & 0.06 & 0.06 & 0.95 & 0.92 \\
\hline oct & 9.17 & 0.14 & 14.25 & 9.50 & 0.05 & 0.03 & 0.70 & 0.72 & 0.16 & 0.13 & 12.96 & 8.63 & 9.04 & 9.03 & 0.88 & 0.90 \\
\hline Nov & 0.13 & 0.11 & 14.59 & 11.40 & 0.03 & 0.02 & 0.72 & 0.71 & 0.12 & 0.10 & 13.26 & 10.36 & 0.03 & 0.02 & 0.90 & $0.8 s$ \\
\hline Dec & $0.1 \mathrm{~s}$ & 0.19 & 17.36 & 17.91 & o.es & 0.09 & 0.67 & 0.65 & 0.16 & 0.17 & 15.78 & 16.28 & 0.05 & 0.09 & 0.84 & 0.82 \\
\hline
\end{tabular}


Table 3 Comparison of MAE and MARE between the ANN Scenario I. II and III and HGS methods

\begin{tabular}{|c|c|c|c|c|c|c|c|c|c|c|}
\hline \multirow{4}{*}{ Month } & \multicolumn{5}{|c|}{ MAE } & \multicolumn{5}{|c|}{ MARE } \\
\hline & \multirow{3}{*}{ HGS } & \multicolumn{4}{|c|}{ ANN } & \multirow{3}{*}{ HGS } & \multicolumn{4}{|c|}{ ANN } \\
\hline & & \multicolumn{2}{|c|}{ Scentano I } & \multicolumn{2}{|c|}{ Scenario II } & & \multicolumn{2}{|c|}{ ScenanoI } & \multicolumn{2}{|c|}{ Scenario II } \\
\hline & & $1986-87$ & $19 \$ 8$ & $1986-87$ & 1988 & & $1986-87$ & 1988 & $1986-87$ & 1988 \\
\hline Jan & 0.938 & 0.127 & 0.135 & 0.149 & 0.165 & 60.766 & $13.97 \mathrm{~s}$ & 14.857 & $\$ .902$ & 7.263 \\
\hline Feb & 0.425 & 0.114 & 0.125 & 0.151 & 0.131 & 35,244 & 10.495 & 11369 & 8.005 & 12807 \\
\hline MaI & 0.392 & 0.115 & 0.124 & 0.084 & 0.133 & 22419 & 8911 & 10588 & 6.258 & 8356 \\
\hline Apr & 0.572 & 0.158 & 0.137 & 0.147 & 0.151 & 20.241 & 6.139 & 5.55 & 5.435 & 7.127 \\
\hline May & 0.741 & 0.21 & 0.241 & 0.163 & 0.134 & 20.335 & 6073 & 7.523 & 4.364 & 4.355 \\
\hline Jun & 0.832 & 0.185 & 0.241 & 0.212 & 0.201 & 19.536 & 4.811 & 5.59 & 5.067 & 4.717 \\
\hline Jul & 0.884 & 0.239 & 0.283 & 0.190 & 0.260 & 20.352 & 5.662 & 7.3 & 4.590 & 6.677 \\
\hline Aug & 0.810 & 0.253 & 0.259 & 0.223 & 0.212 & 21.225 & 6879 & 8.593 & 5952 & 6.529 \\
\hline Sep & 0.699 & 0.194 & 0.23 & 0.152 & 0.145 & 24974 & 6.776 & 9.756 & 6.046 & 4.791 \\
\hline Oct & 0.615 & 0.157 & 0.131 & 0.099 & 0.100 & 36,753 & 12.955 & 8.634 & 6.738 & 6.079 \\
\hline Nov & 0.613 & $0.11 \mathrm{~s}$ & 0.1 & 0.102 & 0.113 & 58034 & 13.262 & 10.363 & 11.050 & 9.929 \\
\hline Dec & 0.989 & 0.162 & 0.174 & 0115 & $012^{7}$ & 79.018 & 15.781 & 16.278 & 11.272 & 12.427 \\
\hline
\end{tabular}

Table 4 Comparison of MSE and $\mathrm{R}^{2}$ between the ANN Scenario I. II and III and HGS methods

\begin{tabular}{|c|c|c|c|c|c|c|c|c|c|c|}
\hline \multirow{4}{*}{ Month } & \multicolumn{5}{|c|}{ MSE } & \multicolumn{5}{|c|}{$\mathrm{R}^{2}$} \\
\hline & \multirow{3}{*}{ HGS } & \multicolumn{4}{|c|}{ ANN } & \multirow{3}{*}{ HGS } & \multicolumn{4}{|c|}{ ANN } \\
\hline & & \multicolumn{2}{|c|}{ Scenariol } & \multicolumn{2}{|c|}{ Scenario II } & & \multicolumn{2}{|c|}{ Scenano I } & \multicolumn{2}{|c|}{ Scenanio II } \\
\hline & & $1986-87$ & 1988 & $1986-87$ & 1988 & & $1986-87$ & 1988 & $1986-87$ & 1988 \\
\hline Jan & 0.883 & 0.033 & 0.037 & 0.035 & 0.038 & 0.394 & 0.953 & 0.93 & 0.905 & 0.927 \\
\hline Feb & 0.451 & 0.028 & 0.033 & 0.035 & 0.025 & 0.504 & 0.956 & 0.944 & 0928 & 0.934 \\
\hline Mar & 0.290 & 0.023 & 0.031 & 0.013 & 0.033 & 0.756 & $0.8 \$ 1$ & 0.871 & 0.92 & 0.906 \\
\hline Apr & 0.511 & 0.045 & 0.031 & 0.037 & 0.038 & 0.778 & 0.947 & 0.91 & 0.955 & 0.94 \\
\hline May & 0.671 & 0.074 & 0.097 & 0.058 & 0.026 & 0.896 & 0938 & 0.9 & 0.934 & 0.964 \\
\hline Jun & 0.828 & 0.047 & $0.0 \$ 6$ & 0.052 & 0.057 & 0.857 & 0.935 & 0.863 & 0.918 & 0.859 \\
\hline $\mathrm{Jul}$ & 0.821 & 0.086 & 0.098 & 0.059 & 0.084 & 0.827 & 0.86 & 0.863 & 0.888 & 0.877 \\
\hline Aug & 0.801 & 0.11 & 0.097 & 0.078 & 0.064 & 0.862 & 0.86 & 0.857 & 0.92 & 0925 \\
\hline Sep & 0.609 & 0.062 & 0.063 & 0.035 & 0.041 & 0.889 & 0948 & 0.915 & 0.957 & 0.937 \\
\hline Oct & 0.503 & 0.042 & 0.026 & 0.025 & 0.018 & 0.674 & 0.876 & 0,895 & 0.875 & 0.913 \\
\hline Nov & 0.703 & 0.025 & 0.017 & 0.021 & 0.019 & 0.280 & 0.9 & $0.8 \$ 2$ & 0918 & 0.85 \\
\hline Dec & 0.857 & 0.076 & 0.085 & 0.035 & 0.037 & 0.288 & 0.84 & 0.816 & 0.88 & 0.868 \\
\hline
\end{tabular}


Table 5 Comparison of MAE and MARE between the ANN Scenario III ( $\mathrm{P}=0,1,2$ and 3 )

\begin{tabular}{|c|c|c|c|c|c|c|c|c|c|c|c|c|c|c|c|c|}
\hline \multirow{4}{*}{ Month } & \multicolumn{8}{|c|}{ MAE } & \multicolumn{8}{|c|}{ MLARE } \\
\hline & \multicolumn{8}{|c|}{ Scenario III } & \multicolumn{8}{|c|}{ Scenario III } \\
\hline & \multicolumn{2}{|c|}{$P=0$} & \multicolumn{2}{|c|}{$P=1$} & \multicolumn{2}{|c|}{$P=2$} & \multicolumn{2}{|c|}{$P=3$} & \multicolumn{2}{|c|}{$P=0$} & \multicolumn{2}{|c|}{$P=1$} & \multicolumn{2}{|c|}{$P=2$} & \multicolumn{2}{|c|}{$P=3$} \\
\hline & 1986.87 & 1958 & 1986.87 & 1988 & $1986-87$ & 1985 & 1986-87 & 1988 & $1986-87$ & 1988 & $1986-87$ & 1988 & 1986.87 & 19880 & $1986-87$ & 1958 \\
\hline Jan & 0.102 & $0.10 s$ & 0.091 & 0.097 & 0.073 & 0.078 & 0.122 & 0.130 & $8.38^{7}$ & 7.429 & 7.548 & 6.686 & 6.039 & 5.349 & 10.064 & \$.915 \\
\hline Feb & $0.08 \theta$ & e.0ss & 0.076 & 0.083 & 0.061 & 0.067 & 0.104 & 0.114 & 7,347 & 7.958 & 6.980 & 7.560 & 5.584 & 6.048 & 9.551 & 10.345 \\
\hline Mar & $0.09 \mathrm{~s}$ & 0.105 & 0.083 & 0.090 & 0.066 & 0.072 & 0.137 & 0.148 & -.574 & 7.941 & 6.438 & 6.750 & 5.150 & 5.400 & 10.604 & 11.117 \\
\hline Apr & 0.142 & 0.123 & $0.12 \mathrm{~s}$ & 0.111 & $0.0^{77}$ & 0.067 & 0.192 & 0.166 & 5.525 & 4.995 & 4.973 & 4.496 & 2.984 & 2.697 & 7.459 & 6.743 \\
\hline May & 0.158 & 0.181 & 0.150 & 0.172 & $\theta .090$ & 0.103 & 0.165 & 0.190 & 4.555 & 4.890 & 4.327 & 4.646 & 2.596 & 2.787 & 4.783 & 5.135 \\
\hline Jun & 0.130 & 0.169 & 0.104 & 0.135 & 0.083 & 0.108 & 0.142 & 0.186 & $3.36 \mathrm{~S}$ & 3.913 & 2.694 & 3.130 & 2.156 & 2.504 & 3.705 & 4.304 \\
\hline JnI & 0.191 & 0.226 & 0.172 & 0.204 & $0.0 \$ 6$ & 0.102 & 0.268 & $0.31^{7}$ & 4.530 & 5.840 & 4.077 & 5.256 & 2.039 & 2.628 & 6.342 & 5.176 \\
\hline Aug & 0.190 & 0.194 & 0.150 & 0.185 & 0.090 & 0.092 & 0.228 & 0.233 & 5.159 & 6.445 & 4.901 & 6.123 & 2.451 & 3.061 & 6.191 & 7.734 \\
\hline Sep & 0.136 & 0.161 & 0.122 & 0.145 & 0.086 & 0.101 & 0.149 & 0.177 & 4.743 & 5.366 & 4.269 & 4.829 & 2.988 & 3.381 & 5.217 & 5.903 \\
\hline Od & 0.094 & 0.079 & 0.075 & 0.063 & 0.068 & 0.057 & 0.099 & 0.083 & 7.773 & 5.180 & 6.218 & 4.144 & 5.597 & 3.730 & 8.162 & 5.439 \\
\hline Nov & 0.094 & 0.050 & 0.080 & 0.068 & 0.064 & 0.054 & 0.123 & 0.104 & 10.610 & 8.290 & 9.019 & 7.047 & 7.215 & 5.637 & 13,793 & 10.777 \\
\hline Dec & 0.113 & 0.122 & 0.105 & 0.113 & 0.084 & 0.091 & 0.136 & 0.146 & 11.047 & 11.395 & 10.274 & 10.597 & 8.219 & 8.478 & 13.256 & 13.674 \\
\hline
\end{tabular}

Table 6 Comparison of MSE and $\mathrm{R}^{2}$ between the ANN Scenario III ( $P=0,1,2$ and 3 )

\begin{tabular}{|c|c|c|c|c|c|c|c|c|c|c|c|c|c|c|c|c|}
\hline \multirow{4}{*}{ Month } & \multicolumn{8}{|c|}{ MSE } & \multicolumn{8}{|c|}{$\mathbf{R}^{2}$} \\
\hline & \multicolumn{8}{|c|}{ Scenario $\mathrm{II}$} & \multicolumn{8}{|c|}{ Scenario m } \\
\hline & \multicolumn{2}{|c|}{$P=0$} & \multicolumn{2}{|c|}{$P=1$} & \multicolumn{2}{|c|}{$P=2$} & \multicolumn{2}{|c|}{$P=3$} & \multicolumn{2}{|c|}{$P=0$} & \multicolumn{2}{|c|}{$P=1$} & \multicolumn{2}{|c|}{$P=2$} & \multicolumn{2}{|c|}{$P=3$} \\
\hline & 1986.87 & 1985.000 & 1986.87 & 1958.600 & $1986-8=$ & 1985.000 & $1986-87$ & 1958.000 & 1996.87 & 1958.000 & $1986-87$ & 1985.000 & 1986.87 & 1958.000 & 1956.87 & 1958.000 \\
\hline Jan & 0.026 & 0.030 & 0.023 & 0.027 & 0.012 & 0.022 & 0.031 & 0.036 & 0.920 & 0.947 & 0.953 & 0.930 & 0.982 & 0.958 & 0.874 & 0.900 \\
\hline Feb & 0.020 & 0.020 & 0.019 & 0.019 & 0.010 & 0.015 & 0.026 & 0.026 & 0.940 & 0.944 & 0.956 & 0.944 & 0.955 & 0.972 & 0.893 & 0.897 \\
\hline Mar & 0.020 & 0.026 & 0.017 & 0.022 & 0.011 & 0.018 & 0.028 & 0.036 & 0.930 & 0.926 & 0.881 & 0.871 & 0.907 & 0.897 & 0.854 & o.sse \\
\hline Apr & $0.0+1$ & $0.02 s$ & 0.037 & 0.025 & 0.002 & 0.015 & $0.0 \leq 5$ & 0.038 & 0.955 & 0.950 & 0.947 & 0.910 & 0.975 & 0.937 & $0.90^{7}$ & 0.903 \\
\hline May & 0.056 & 0.019 & $0.0 \leqslant 3$ & 0.018 & 0.003 & 0.011 & 0.059 & 0.020 & 0.954 & 0.964 & 0.938 & 0.900 & 0.966 & 0.927 & 0.906 & 0.916 \\
\hline Jun & 0.033 & 0.043 & 0.026 & 0.034 & 0.017 & 0.028 & 0.036 & 0.047 & 0.930 & 0.920 & 0.935 & 0.563 & 0.963 & 6.859 & 0.884 & 0.874 \\
\hline Jut & 0.069 & $0.07 \mathrm{~s}$ & 0.062 & 0.070 & 0.031 & 0.035 & 0.097 & 0.109 & 0.890 & 0.877 & 0.860 & 0.863 & 0.856 & 0.839 & 0.846 & $0 . \$ 33$ \\
\hline Ang & 0.083 & 0.049 & 0.079 & 0.047 & 0.009 & 0.023 & 0.100 & 0.059 & 0.930 & 0.925 & 0.860 & 0.857 & 0.886 & 0.883 & 0.854 & 0.879 \\
\hline Sep & 0.043 & 0.032 & 0.039 & 0.029 & 0.007 & 0.020 & 0.047 & 0.035 & 0.957 & 0.940 & 0.948 & 0.915 & 0.976 & 0.942 & 0.909 & 0.893 \\
\hline odt & 0.025 & 0.016 & 0.020 & 0.013 & 0.008 & 0.012 & 0.026 & 0.017 & 0.875 & 0.913 & 0.876 & 0.895 & 0.902 & 0.922 & 0.831 & 0.867 \\
\hline Nov & 0.020 & 0.614 & 0.017 & 0.012 & 0.009 & 0.010 & 0.026 & 0.018 & 0.918 & 0.850 & 0.900 & 0.882 & 0.927 & 0.908 & 0.872 & $0.80 s$ \\
\hline Dec & 0.053 & 0.017 & 0.049 & 0.016 & 0.039 & 0.013 & 0.064 & 0.020 & 0.850 & 0.568 & 0.840 & 0.816 & 0.565 & 0.540 & 0.836 & 0.825 \\
\hline
\end{tabular}


Table 7 Classical ANN scenario III and ensemble ANN per formance based on the peak and low flow error criteria

\begin{tabular}{ccccccc}
\hline \multirow{2}{*}{ Month } & \multicolumn{3}{c}{ Classical ANN Scenario III } & \multicolumn{2}{c}{ Ensemble ANN Scenario III } \\
\cline { 2 - 7 } & PVC $(\%)$ & LVC $(\%)$ & Average $\%$ & PVC $(\%)$ & LVC $(\%)$ & Average $\%$ \\
\hline Jan & 1.76 & 3.36 & 2.56 & 1.32 & 2.52 & 1.92 \\
Feb & 3.86 & 3.72 & 3.79 & 3.09 & 2.79 & 2.94 \\
Mar & 5.27 & 4.68 & 4.98 & 3.16 & 3.51 & 3.34 \\
Apr & 6.53 & 3.56 & 5.04 & 4.57 & 2.67 & 3.62 \\
May & 4.06 & 1.95 & 3.00 & 3.65 & 1.46 & 2.56 \\
Jun & 4.94 & 1.28 & 3.11 & 3.45 & 0.64 & 2.05 \\
Jul & 5.11 & 3.78 & 4.45 & 2.56 & 2.65 & 2.60 \\
Aug & 4.77 & 1.44 & 3.10 & 2.38 & 1.15 & 1.77 \\
Sep & 2.57 & 3.21 & 2.89 & 1.54 & 2.89 & 2.21 \\
Odt & 2.75 & 2.16 & 2.46 & 1.79 & 1.73 & 1.76 \\
Nov & 3.53 & 1.13 & 2.45 & 2.68 & 0.73 & 1.70 \\
Dec & 6.02 & 4.08 & 5.05 & 4.52 & 3.06 & 3.79 \\
\hline
\end{tabular}

Table 8: MAE, MARE, MSE and R2 associated with ENN model Scenario III $(P=2)$ for the year 1988 lead time for three days ahead

\begin{tabular}{||c||c|c|c|c||}
\hline \multicolumn{1}{||}{} & \multicolumn{5}{||}{ MSE } \\
\cline { 2 - 5 } Month & \multicolumn{2}{|c||}{ First approach } & \multicolumn{2}{c||}{ Second approach } \\
\cline { 2 - 5 } & $\mathrm{L}=2$ & 0.018 & $\mathrm{~L}=2$ & $\mathrm{~L}=3$ \\
\hline \multirow{2}{*}{ Jan } & 0.013 & 0.015 & 0.017 \\
Feb & 0.012 & 0.017 & 0.015 & 0.018 \\
Mar & 0.015 & 0.019 & 0.019 & 0.027 \\
May & 0.003 & 0.005 & 0.004 & 0.005 \\
Jun & 0.045 & 0.069 & 0.066 & 0.080 \\
Jul & 0.069 & 0.164 & 0.063 & 0.150 \\
Aug & 0.077 & 0.184 & 0.086 & 0.140 \\
Sep & 0.016 & 0.152 & 0.019 & 0.132 \\
Oct & 0.013 & 0.024 & 0.014 & 0.026 \\
Nov & 0.012 & 0.014 & 0.014 & 0.022 \\
Dec & 0.018 & 0.034 & 0.022 & 0.041 \\
\hline \hline
\end{tabular}




\section{University Library}

\section{- M M N E R VA A gateway to Melbourne's research publications}

Minerva Access is the Institutional Repository of The University of Melbourne

\section{Author/s:}

El-Shafie, A;Alsulami, HM;Jahanbani, H;Najah, A

Title:

Multi-lead ahead prediction model of reference evapotranspiration utilizing ANN with ensemble procedure

\section{Date:}

2013-08-01

\section{Citation:}

El-Shafie, A., Alsulami, H. M., Jahanbani, H. \& Najah, A. (2013). Multi-lead ahead prediction model of reference evapotranspiration utilizing ANN with ensemble procedure. STOCHASTIC ENVIRONMENTAL RESEARCH AND RISK ASSESSMENT, 27 (6), pp.1423-1440. https://doi.org/10.1007/s00477-012-0678-6.

Persistent Link:

http://hdl.handle.net/11343/282884 